Research Article

\title{
Effect of Different Types of Middle Columns on the Seismic Performance of Single-Story Subway Station Structure
}

\author{
Sheng Li, ${ }^{1}$ Haiyang Zhuang $\mathbb{D}^{1,}{ }^{1,2}$ Wei Wang, ${ }^{1}$ Liguo Jin, ${ }^{1}$ and Zhengfang Dong ${ }^{3}$ \\ ${ }^{1}$ Institute of Geotechnical Engineering, Nanjing Tech University, 200 Zhongshan North Road, Nanjing 210009, China \\ ${ }^{2}$ Civil Engineering and Earthquake Disaster Prevention Center of Jiangsu Province, 200 Zhongshan North Road, \\ Nanjing 210009, China \\ ${ }^{3}$ Institute of Geotechnical and Rail Transport Engineering, Henan University, 85 Minglun Road, Kaifeng 475004, China \\ Correspondence should be addressed to Haiyang Zhuang; zhuang7802@163.com
}

Received 9 June 2021; Accepted 28 July 2021; Published 4 August 2021

Academic Editor: Piguang Wang

Copyright (c) 2021 Sheng Li et al. This is an open access article distributed under the Creative Commons Attribution License, which permits unrestricted use, distribution, and reproduction in any medium, provided the original work is properly cited.

\begin{abstract}
In view of the seismic weak component of the single-frame-type subway station structure, the three-dimensional (3D) timedomain nonlinear finite element static-dynamic coupling analysis model of interaction between soil and subway station structure is established by, respectively, using rectangular reinforced concrete (RRC) columns, circular reinforced concrete (CRC) columns, and prefabricated concrete-filled steel tube (CFST) columns with a quick-connection device proposed in this article. This analysis model is further used to investigate the influence of different types of middle columns on the seismic response characteristics of the underground structure, such as the interstory displacement angle, seismic damage, and dynamic response. The results show that, compared with the rectangular columns, the circular columns with the equal moment of inertia suffer less damage in the earthquake and have better seismic performance. The prefabricated CFST columns can effectively ensure that the middle columns of the station structure are not severely damaged and can be replaced quickly after the earthquake, which improves the overall seismic performance of the subway station structure and the rapid recovery ability of the structural function after the earthquake.
\end{abstract}

\section{Introduction}

With the continuous progress of urbanization in China, more and more cities begin to build urban rail transit and gradually adopt prefabricated structures for infrastructure construction to alleviate the increasingly serious traffic congestion $[1,2]$. As a matter of fact, most of the existing underground subway structures have not been subjected to the severe test of the strong earthquake. Whether they can withstand the destructive effect of the strong earthquake still needs to be further studied $[3,4]$. This was especially true during the Hanshin earthquake in Japan on 17 January 1995; under the action of this strong earthquake, a large area of subway underground station structures and tunnels suffered serious damages $[5,6]$. More than half of the structural columns in the underground station of the DAIKAI Metro in Kobe city collapsed completely, resulting in the collapse of the whole structural roof, and the largest ground displacement was nearly $2.5 \mathrm{~m}$ [7-9]. On the other hand, most of the subway stations are deeply buried underground with great difficulty in construction, high design demand, and complicated maintenance. As an important part of the urban underground lifeline project, the damage of the subway station will cause huge social impact and economic loss. Therefore, the study on the seismic performance and seismic failure mechanism of subway station structure has become a hot and difficult topic in the field of urban earthquake prevention and mitigation [10].

The existing research shows that the roof and the middle columns of the subway station structure will be seriously damaged in the earthquake process. Particularly, the incongruous resistance of sidewall and middle column to horizontal shear deformation increases significantly, and the horizontal resistance of middle column to shear deformation weakens significantly, leading to brittle failure and loss of vertical bearing capacity [11]. In addition, due to the 
complex structure of the subway station, how to quickly repair the station structure after the earthquake is also an urgent problem to be solved. In view of the above-mentioned problems, some scholars have carried out relevant research work on how to improve the seismic performance of the middle columns of the subway station structures. The existing research results show that setting up a special device at the end of the columns can effectively reduce the lateral deformation and seismic damage of the columns [12-14]. Unfortunately, under the action of strong earthquakes, the deformation and destruction of the subway station structure will be restricted and affected by the deformation of the surrounding soil, so the mechanism of the nonlinear dynamic interaction between the soil and the station structure is very complicated. The existing researches on the earthquake damage mechanism of the large and complex subway station structure and the protection methods of the middle columns are still in the development stage, especially the research on postearthquake repair technology of underground structures $[15,16]$.

Based on the seismic damage characteristics of the DAIKAI metro station in Japan, the prefabricated concretefilled steel tube (CFST) column and its quick-connection device were proposed to improve the repairable performance of the middle columns in the most severely damaged subway station structure. Based on the large commercial finite element software ABAQUS ${ }^{\circledR}$, a three-dimensional global time-domain finite element analysis model was established for the nonlinear static-dynamic coupling interaction of soil-underground structure. The seismic response characteristics (the lateral deformation, the seismic damage, and the response of dynamic internal force) of the three different types of middle columns (rectangular reinforced concrete column, circular reinforced concrete column, and prefabricated concrete-filled steel tube column) in subway station structures under the action of different input bedrock ground motions were systematically studied. We were delighted to find that the prefabricated concrete-filled steel tube (CFST) columns with the quick-connection device proposed by this article can effectively improve the seismic performance of the underground structures and have the ability to quickly repair after an earthquake. The results can provide reasonable reference and guidance for the engineering practice of seismic isolation technology for the subway station structure.

\section{Finite Element Model}

2.1. Main Dimensions of the DAIKAI Metro Station. The DAIKAI metro station in Japan was adopted as the research object. DAIKAI metro station is one of the structures which have suffered the most severe earthquake damage since modern times. The cross section size of the main structure of the station is shown in Figure 1. The letter L represents the longitudinal beam. In addition, the overburden layer thickness of the station is $4.8 \mathrm{~m}$, the cross section width of the main structure of the station is $17 \mathrm{~m}$, and the overall height of the structure is $7.17 \mathrm{~m}$. The roof thickness of the main structure of the station is $0.8 \mathrm{~m}$, the floor thickness is
$0.85 \mathrm{~m}$, and the width of the sidewall is $0.7 \mathrm{~m}$. Furthermore, the columns in the prototype station structure are rectangular with $0.4 \mathrm{~m}$ width and $1 \mathrm{~m}$ length, along the longitudinal direction, being $3.5 \mathrm{~m}$ apart. For the distribution of steel rebar on the cross section, please refer to [9].

\subsection{Boundary Conditions of the Soil and Dynamic Damage} Constitutive Model of Concrete. The constitutive model of the soil in the site is a nonlinear dynamic constitutive model of soft soil memory viscoelastic-plastic nesting surface in the form of total stress increment established by Zhuang and Chen [17]. This model is based on the generalized geotechnical plasticity theory and the hardening modulus criterion combining isotropic hardening and dynamic hardening $[17,18]$. The constitutive model has been coded by the Fortran ${ }^{\circledR}$ computer language as a subroutine of ABAQUS ${ }^{\circledR}$ by the authors. The relationship between the static compressive confining stress and the initial dynamic shear modulus of soil is as follows:

$$
\begin{aligned}
G_{o} & =\rho V_{S}^{2}\left(\frac{p}{p_{0}}\right)^{0.5}, \\
p & =\frac{\sigma_{1}+\sigma_{2}+\sigma_{3}}{3},
\end{aligned}
$$

where $G_{o}$ is the initial dynamic shear modulus of the soil, $\rho$ is the soil density, $p_{0}$ is the initial static compressive confining stress of the soil elements, and $\sigma_{1}, \sigma_{2}$, and $\sigma_{3}$ represent the components of the static stress condition of the soil elements after the construction of the underground structure.

In this study, the basic physical and mechanical parameters of soil in each layer of the site are shown in Table 1. The constitutive model of concrete material adopts the dynamic viscoplastic damage model of concrete under cyclic dynamic load, which was perfected by Lee and Fenves [19]. It is obtained by the concrete plastic damage model proposed by [20]. Based on the fracture energy principle of concrete materials, two damage variables are used to describe the two different stiffness decay laws of concrete materials during tensile failure and compression failure, respectively. The yield function of several hardening variables of concrete is modified in the constitutive model, which can well reflect the damage evolution state of the concrete under a strong earthquake. For the specific parameters of the dynamic viscoplastic damage model of C30 concrete used in this study, please refer to $[21,22]$. In addition, the linear elastic constitutive model is adopted for the reinforcement material, whose elastic modulus is $210 \mathrm{GPa}$. Rayleigh damping is used to approximate the damping of both concrete and soil materials. The initial damping ratio of concrete material is $2 \%$, and that of soil material is $3 \%[23,24]$.

2.3. Prefabricated CFST Column. Studies on the seismic performance of the main structure of the DAIKAI subway station and its earthquake damage have shown that the middle columns of the single-story subway station structure are prone to serious earthquake damage under the action of 


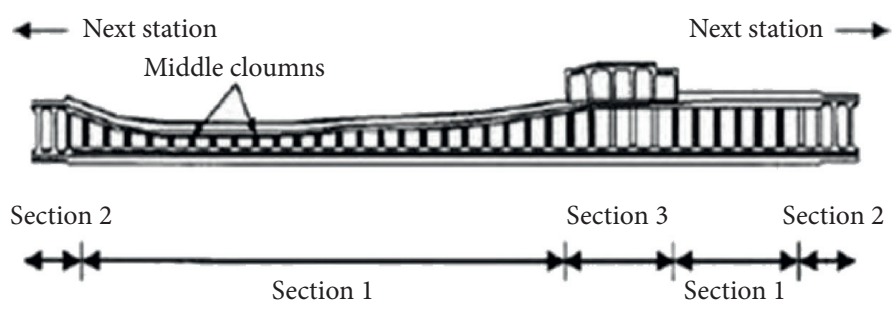

(a)

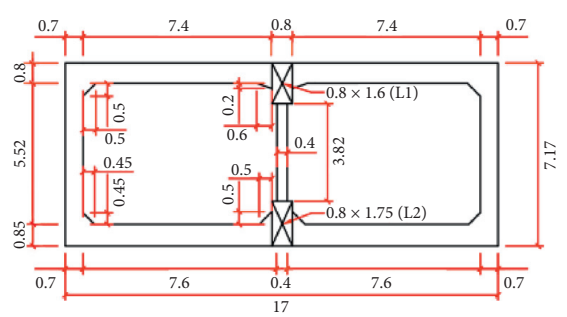

(b)

FIGURE 1: Main dimensions of DAIKAI metro station. (a) Longitudinal schematic of the DAIKAI metro station. (b) Details of section 1 (unit: $\mathrm{m}$ ).

TABle 1: Physical parameters of soils.

\begin{tabular}{|c|c|c|c|c|c|c|}
\hline The soil information & Depth (m) & $\begin{array}{c}\text { Density } \\
\left(\mathrm{kg} \cdot \mathrm{m}^{-3}\right) \\
\end{array}$ & $\begin{array}{c}\text { Shear wave velocity } \\
\left(\mathrm{m} \cdot \mathrm{s}^{-1}\right)\end{array}$ & $\begin{array}{l}\text { Poisson's } \\
\text { ratio }\end{array}$ & $\begin{array}{c}\text { Cohesive force } \\
(\mathrm{kPa})\end{array}$ & $\begin{array}{c}\text { Internal friction } \\
\left({ }^{\circ}\right)\end{array}$ \\
\hline Artificial filled soil & $0 \sim 1.0$ & 1900 & 140 & 0.33 & 20 & 15 \\
\hline Holocene sandy soil & $1.0 \sim 5.1$ & 1900 & 140 & 0.32 & 1 & 40 \\
\hline Holocene sandy soil & $5.1 \sim 8.3$ & 1900 & 170 & 0.32 & 1 & 40 \\
\hline Pleistocene clay & $8.3 \sim 11.4$ & 1900 & 190 & 0.4 & 30 & 20 \\
\hline Pleistocene clay & $11.4 \sim 17.2$ & 1900 & 240 & 0.3 & 30 & 20 \\
\hline $\begin{array}{l}\text { Pleistocene sandy } \\
\text { soil }\end{array}$ & $17.2 \sim 39.2$ & 2000 & 330 & 0.26 & 1 & 40 \\
\hline
\end{tabular}

an earthquake $[25,26]$. The prefabricated structure has the characteristics of easy disassembly and high strength, which can provide better repair for the station structure. In engineering practice, the prefabricated CFST column mostly adopts the circular structure rather than the rectangular structure. Given this, based on the principle of the equal moment of inertia of section, the rectangular concrete section of the middle column of the original structure in working condition 1 was first converted into a circular concrete section with the same flexural rigidity. The traditional structure with the circular middle columns was regarded as working condition 2 . The reinforcement of the main structure and the middle columns in working condition 1 was the same as that in working condition 2 . Furthermore, according to the size of the circular columns, a quick-connection device was set at the middle columns of the subway station. The concrete label of traditional columns is the same as that prefabricated concrete-filled steel tube columns, as well as the steel model. The structure with prefabricated concrete-filled steel tube columns was regarded as working condition 3 . Figures 2(a) and 2(b) show the specific setting location of the prefabricated concrete-filled steel tube column quickconnection device.

The column with quick-connection device consists of the prefabricated CFST column, the upper and lower fittings, the bolts and gaskets, and the beams. It is connected through the bolts embedded in the beam. The steel ring joint is divided into left and right parts. Full-seam welding is used between the two rings to enclose the prefabricated CFST column. In the process of establishing the finite element analysis model, the station structure was simplified appropriately. The moment of inertia of the rectangular section is determined by

$$
I_{Z}=\frac{b h^{3}}{12},
$$

where $I_{Z}$ is the moment of inertia of the section about the principal centroidal axis $z, b$ is the width of the section, and $h$ is the height of the section relative to the force direction.

The moment of inertia of the round section is determined by

$$
I_{Z}=\frac{\pi d^{4}}{64},
$$

where $d$ represents the diameter of the circular section. To control variables, the dimensions of the prefabricated CFST column in condition 3 were set to be the same as the dimensions of the concrete column in condition 2 . The prefabricated CFST column is composed of the outer steel skin and the concrete core. In order to facilitate the mass production in engineering practice, the outer diameter of CFST column is rounded to $0.6 \mathrm{~m}(60 \mathrm{~cm})$, and the thickness of outer steel tube is $1 \mathrm{~cm}$. The quick-connection device is composed of an upper semiannular cladding joint and a bearing platform. The outer diameter of the upper semiannular cladding joint is $70 \mathrm{~cm}$, and the thickness is $5 \mathrm{~cm}$. In addition, the thickness of the lower steel plate is $4 \mathrm{~cm}$. The width of the steel bearing platform is the same as the width of the longitudinal beam, and it is riveted on the railway station by bolts.

2.4. Input of Bedrock Motions. In this study, the Kobe wave, El-Centro wave, Wolong wave, and Shifang wave were selected as the horizontal input bedrock motion, and the peak acceleration of input bedrock motion was called PBA for short. The Kobe wave was recorded in the Kobe earthquake in 1995. Its original peak value was $0.85 \mathrm{~g}$, and its duration of 


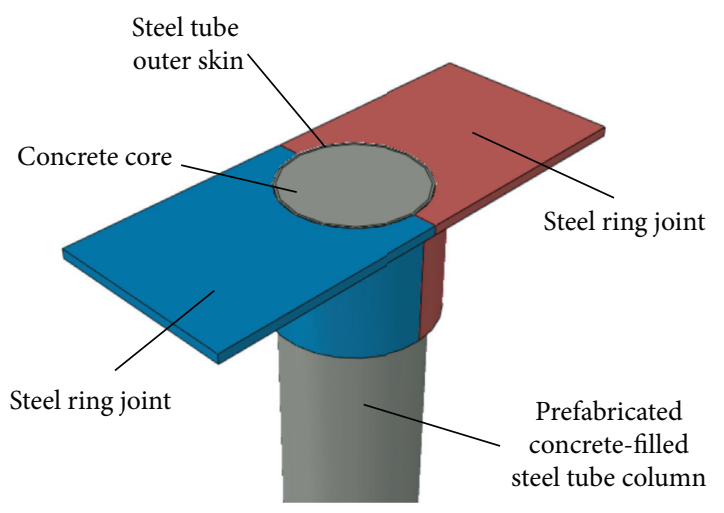

(a)

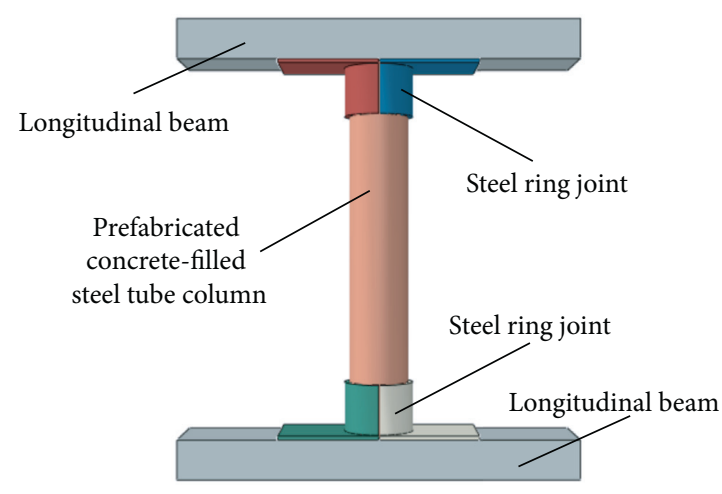

(b)

FIgURE 2: A schematic diagram of the intermediate column quick-connection device. (a) Detailed drawing of ring-wrapped joint. (b) Overall picture of the intermediate column quick-connection device.

strong vibration was about $10 \mathrm{~s}$. The El-Centro wave was recorded by the El-Centro earthquake in southern California. Its original peak value was $0.349 \mathrm{~g}$, and its duration of the strong vibration was about $26 \mathrm{~s}$. Besides, the Wolong wave recorded in Wenchuan earthquake of China was used, the original peak value of which was $0.948 \mathrm{~g}$, belonging to the near-field bedrock motion. The Shifang wave is taken from the NS direction acceleration time history data recorded at Shifang Bajiao station during the Wenchuan earthquake in 2008. The time histories of the four bedrock input motions are shown in Figure 3, and the peak accelerations of the four input motions are adjusted to $0.3 \mathrm{~g}$ and $0.5 \mathrm{~g}$, respectively.

According to the existing studies, when performing seismic response analysis, the choice of input ground motion should consider its vibration frequency; that is, the ratio of peak ground acceleration (PGA) to peak ground velocity $(P G V)$ is used to measure the vibration frequency of input ground motion. When $\mathrm{PGA} / \mathrm{PGV}>1.2$, the input motion belongs to high-frequency motion; for $0.8 \leq \mathrm{PGA} / \mathrm{PGV} \leq 1.2$, the input motion belongs to medium-frequency motion; for $\mathrm{PGA} / \mathrm{PGV}<0.8$, the input motion belongs to low-frequency motion. The PGA/PGV of the Kobe wave is 0.93 and the PGA/PGV of the El-Centro wave is 0.92 , belonging to the medium-frequency input motions. For the Wolong wave, the PGA/PGV is 1.98, belonging to the high-frequency input motion. The PGA/PGV of the Shifang wave is 0.51 , belonging to the low-frequency motion. The input bedrock motions selected in this paper have the characteristics of the high, medium, and low frequencies, respectively.

\subsection{Simulation of Dynamic Contact between Soil and Un-} derground Structure. In this study, the dynamic contact characteristics between the soil and the station structure (or between the main structure of the station and the middle column) and in the quick-connection device are simulated by defining different friction coefficients. The normal contact between the soil and the station structure and the contact surfaces inside the main structure of the station are all defined as follows: when there is tension between the soil and the structure, the corresponding contact surfaces will immediately separate. The tangential contact of the contact surface obeys the Coulomb friction law; namely, when the actual shear stress on each contact surface is greater than the maximum friction limit between the contact surfaces, the contact surface between the soil and the underground structure will be tangential sliding. The friction coefficient between each contact surface in the finite element calculation process is 0.4 [27]. For the subway station structure with the rapid connection device of the CFST column, relative slippage and separation are not allowed between the two steel ring-clad joints and between the ring-clad joints and the longitudinal beams. For the fabricated subway station structure with the CFST columns and quick-connection device, the top/bottom of the middle column may slip with the longitudinal beams of the station structure. The friction coefficient at the surfaces between concrete and concrete is 0.55 , and coefficient between steel tube and concrete is 0.45 . In addition, the steel ring joint and outer skin of prefabricated CFST column are also able to slip during an earthquake, and the friction coefficient between steel and steel is 0.15 [28]. For a subway station structure where the middle column is fully constrained, no relative slippage and separation occur between the two ends of the column and the longitudinal beams.

2.6. Establishment of the Finite Element Model. The finite element analysis method of the nonlinear static and dynamic coupling interaction of the soil-underground structure established by Zhuang and Chen was adopted to consider the influence of the initial static stress state of the surrounding soil foundation on the dynamic response of underground structure [18]. The boundary conditions of the model site need to be converted in the case of the finite element analysis transition from static analysis step to dynamic analysis step $[29,30]$. In the first step for the static analysis, the fixed constraints are adopted at the bottom of the model, and both sides of the boundary are constrained horizontally and free vertically. In the second step, the bottom of the model is subject to vertical constraint and horizontal input bedrock motion, and bearing reaction force (RF) is applied on both sides of the boundary to constrain 


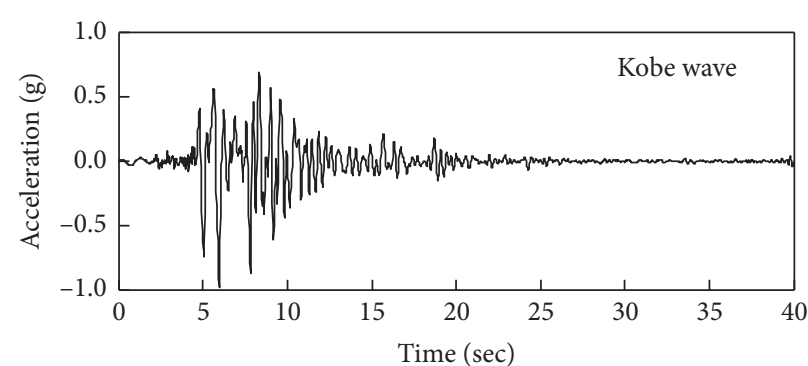

(a)

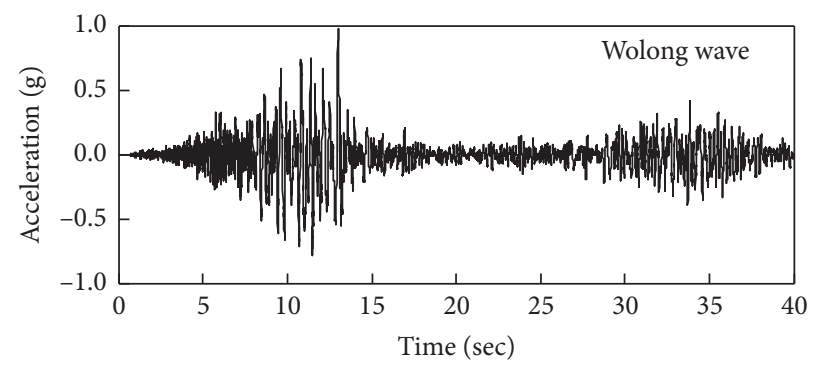

(c)

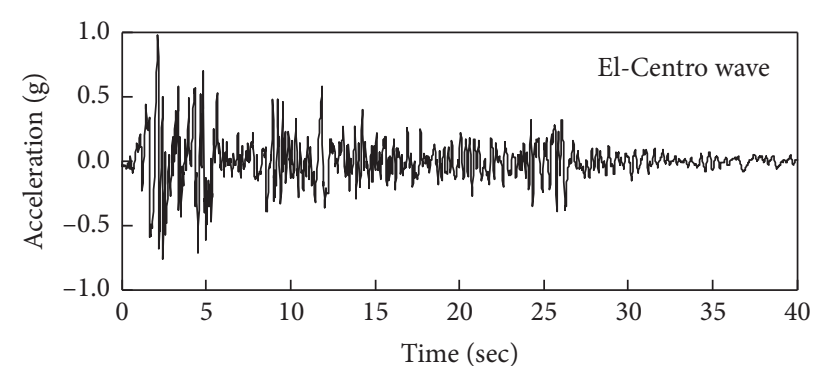

(b)

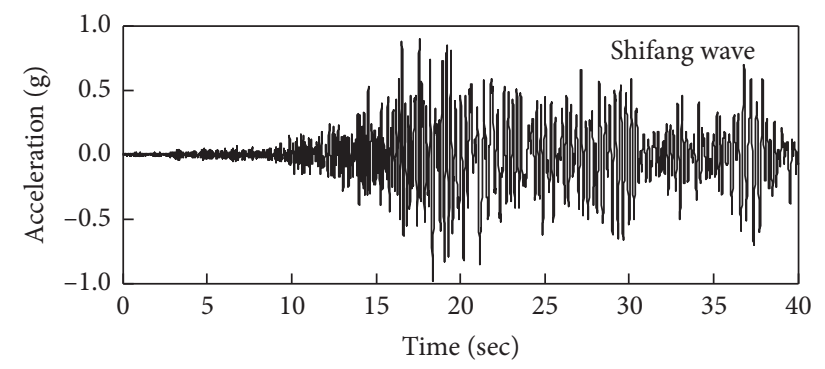

(d)

Figure 3: Time histories of the earthquake waves input from the bedrock surface.

the soil. The transition of boundary conditions is shown in Figure 4. According to Lou et al.'s [21] and Liao's [31] studies, the maximal height of element $h_{\max }$ of the shear motion propagating in the soil should be determined by

$$
h_{\max }=\left(\frac{1}{75} \sim \frac{1}{160}\right) \frac{V_{s}}{f_{\max }},
$$

where $V_{s}$ is the shear velocity and $f_{\max }$ is the maximal vibration frequency of the input motion. To eliminate the impact of the lateral boundary, the width of the model site was $200 \mathrm{~m}$, and the thickness of the model site was $39.2 \mathrm{~m}$. According to equation (4), the maximum element height $h_{\max }$ was between $1 \mathrm{~m}$ and $3 \mathrm{~m}$. Here, the lower values of each range were used to mash the FEM model. The threedimensional FEM model of subway station structure established based on ABAQUS ${ }^{\circledR}$ is shown in Figure 5.

\section{Seismic Reponses of the Underground Structures}

3.1. Interstory Displacement Angle of the Station Structure. Table 2 shows the amplitude of interstory displacement angle (IDA) under different calculation conditions. For different cross section shapes of the column, the displacement angle of structure with CRC columns is less than that with RRC columns. As is shown in Figure 6, when the peak acceleration is $0.3 \mathrm{~g}$, IDA of the structure will be slightly increased when using the CFST column. When the peak acceleration increases from $0.3 \mathrm{~g}$ to $0.5 \mathrm{~g}$, IDA increases rapidly except for very individual calculation cases. Under the excitation of a major earthquake, IDA of the assembled structure is larger than that of the traditional structure with CRC columns and smaller than that of the traditional structure with RRC columns. The reason is that the CRC column has larger lateral stiffness, which can effectively improve the lateral stiffness of the underground structure under the excitation of the seismic motion. IDA of the station decreases slightly when the Wolong wave is input, regardless of whether the structure is with RRC column, CRC column, or CFST column. This is closely related to the strong nonlinear seismic response of the soil layer at the bottom of the subway station structure after the input of the seismic wave, and the severe weakening of the modulus of the soil at the bottom of the subway station structure plays the role of seismic isolation.

In general, the use of the prefabricated CFST columns in some calculation cases will slightly increase IDA of the underground structure. The reason for this phenomenon is that the setting of CFST columns changes the force bearing law of the system. The concrete of the longitudinal beam was no longer directly connected with the middle column, and they slipped relatively under the action of seismic load. As a matter of fact, the constraints between middle column and structure were effectively reduced. If, according to the provisions of 6.9.1 and 6.9.2 in "Standard for Seismic Design of Underground Structure” (GB/T51336-2018, China), the limit value of the elastic IDA of a single-layer underground structure is $1 / 550$, and the limit value of the elastic-plastic IDA is $1 / 250$, compared with the limits set by the above standard, for each input bedrock motion with the same peak acceleration $(\mathrm{PBA}=0.3 \mathrm{~g})$, IDA of the subway station structure in most working conditions is between the limits of the elastic and the elastic-plastic IDAs. However, when subjected to the Wolong wave with $\mathrm{PBA}=0.3 \mathrm{~g}$, IDAs of the underground station structures with the assembled middle columns are close to the limit value of the elastic-plastic IDA, which is in a certain plastic failure state. For the El-Centro wave and the Kobe wave with $\mathrm{PBA}=0.5 \mathrm{~g}$, IDA of the station structure is larger than the limit of the elastic-plastic IDA, 


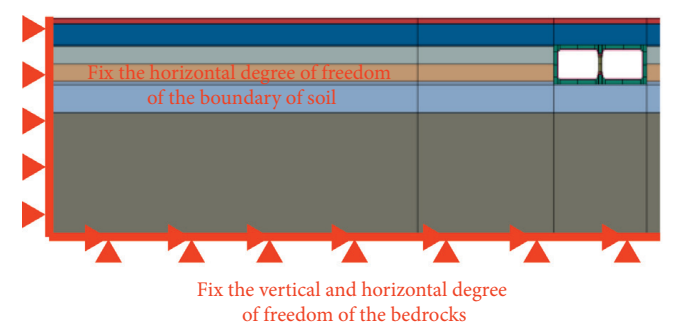

(a)

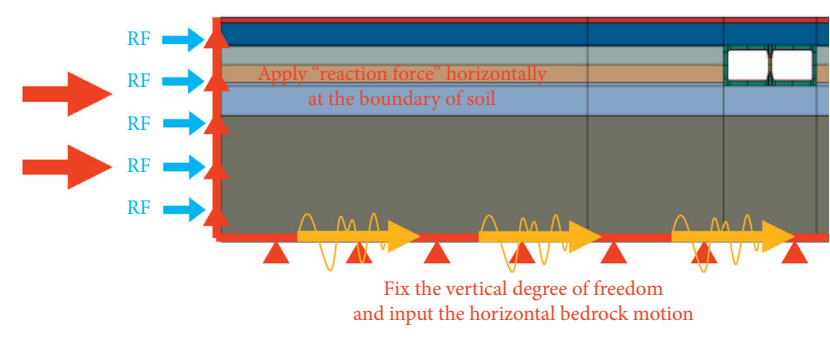

(b)

FIgURe 4: Transition of boundary conditions. (a) Static analysis step. (b) Dynamic analysis step.

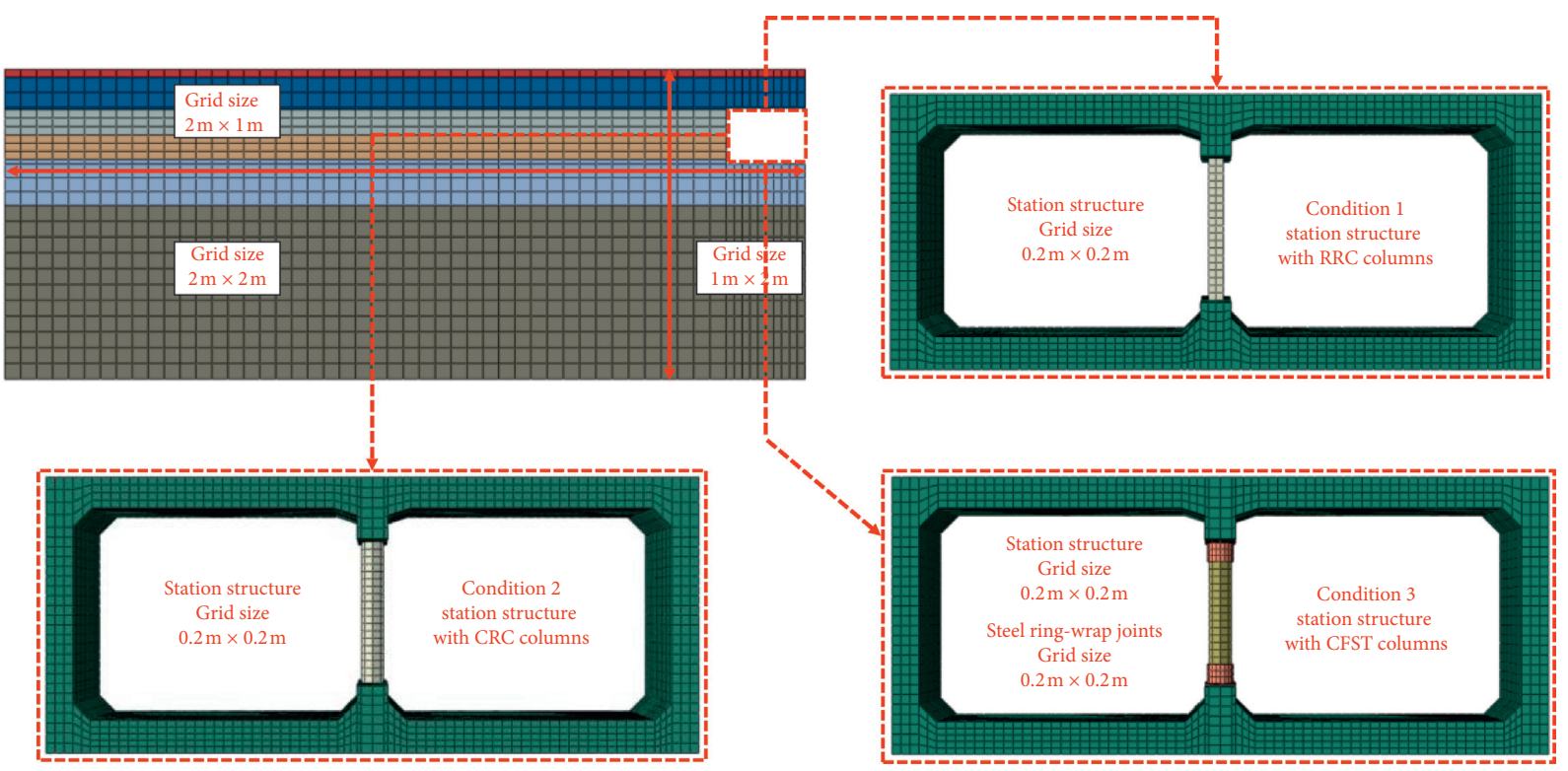

FIGURE 5: Finite element models for the soil-subway station interaction system.

TABLE 2: Comparison of the displacement angle between traditional structure and prefabricated structure (1/1000).

\begin{tabular}{|c|c|c|c|c|}
\hline & Sob & $\begin{array}{l}\text { El-Centro } \\
\text { wave }\end{array}$ & $\begin{array}{l}\text { Wolong } \\
\text { wave }\end{array}$ & $\begin{array}{l}\text { Shifang } \\
\text { wave }\end{array}$ \\
\hline & $\begin{array}{lll}0.3 \mathrm{~g} & 0.5 \mathrm{~g}\end{array}$ & $0.3 \mathrm{~g} \quad 0.5 \mathrm{~g}$ & $\begin{array}{lll}0.3 \mathrm{~g} & 0.5 \mathrm{~g}\end{array}$ & $\begin{array}{lll}0.3 \mathrm{~g} & 0.5 \mathrm{~g}\end{array}$ \\
\hline & 70 & 6 & .512 .2 & 87 \\
\hline & 6. & 4. & 2.20 & 2.6 \\
\hline FST & $1.24 \quad 6.67$ & $3.18 \quad 6.46$ & $2.48 \quad 2.45$ & $2.29 \quad 3.70$ \\
\hline
\end{tabular}

indicating that the structure is in the state of failure. The above analysis is consistent with the actual severe earthquake damage at the DAIKAI station.

For different ground motion inputs, the seismic response characteristics of the underground structure are greatly different. For example, for the Shifang wave with low frequency, the response of the site is intense, and the strength of the soil is weakened obviously, resulting in the softening of the soil beneath the station structure, so it has a certain localized effect. IDA of the station structure with El-Centro and Kobe waves with intermediate frequency is significantly larger than that with Wolong wave (the high-frequency wave). The reason is that the site where the underground structure is located has obvious soft soil site characteristics, making the characteristic period of the site longer. When the

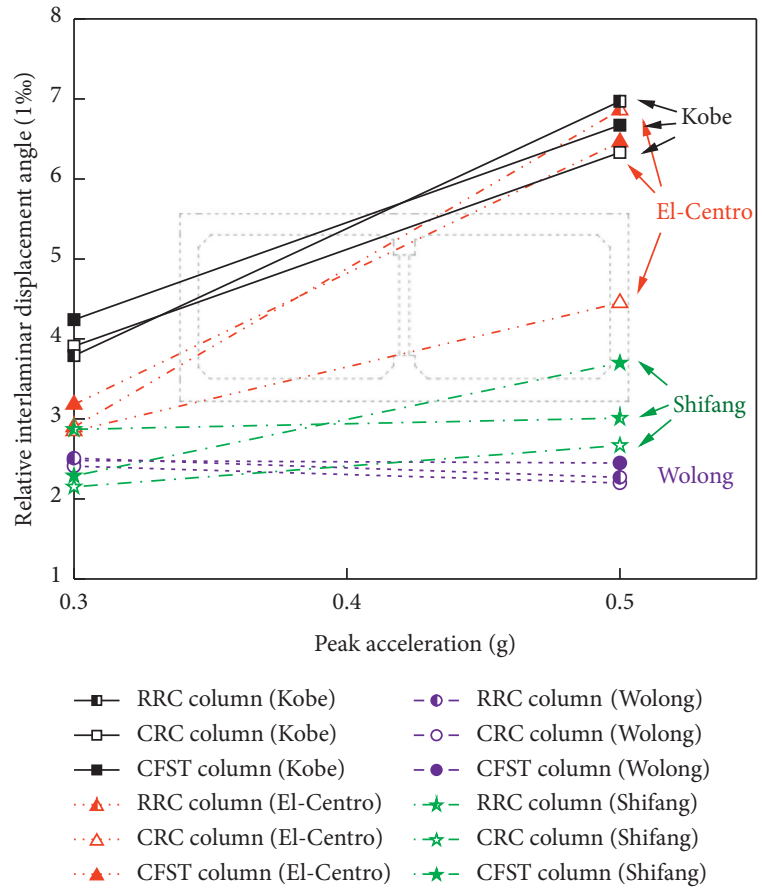

Figure 6: Relationship between the IDA of structure and the PBA of input motion. 
Kobe wave with medium and low frequency is input, the response of the site is the strongest, which leads to a large amount of relative lateral displacement of the soil around the station structure.

\subsection{Acceleration Response of the Underground Structure.} Figure 7 shows the acceleration response amplitudes of the underground structures with the different types of columns. It can be seen that when $\mathrm{PBA}=0.3 \mathrm{~g}$, the peak acceleration at each position of the prefabricated underground structure with CFST columns is smaller than that of the underground structure with nonassembled middle column. However, when $\mathrm{PBA}=0.5 \mathrm{~g}$, the opposite phenomenon can be observed. Previous studies have shown that the seismic response of subway station structure is mainly restricted by the earthquake deformation of the surrounding soil, and the inertial force of the station structure has little effect on its response [32, 33]. It is improper to evaluate the seismic performance of the underground structures according to the acceleration response of the structure like the analysis of above-ground structures. However, for analyzing the response of the equipment in the underground structure, the acceleration response of the underground structure can be used as the floor input motion.

Figures 8 and 9 show the acceleration response spectra of the top and bottom of the station structure corresponding to the three different structure types under the excitation of Kobe wave with $\mathrm{PBA}=0.3 \mathrm{~g}$. Generally, compared with the traditional station structure, the station structure with the prefabricated CFST column has a smaller acceleration at the top plate and a larger one at the bottom plate. For the bottom plate, the response spectrum of the traditional structure with RRC column is relatively close to that of the structure with CRC column, while the response spectrum of the structure with prefabricated CFST middle column increases significantly in $0.2 \mathrm{~s}-0.5 \mathrm{~s}$ and decreases slightly in $0.5 \mathrm{~s}-1 \mathrm{~s}$. For the top plate, the acceleration of the traditional station structure with CRC columns is relatively large within $0.1 \mathrm{~s}$ to $0.3 \mathrm{~s}$, followed by the prefabricated station structure with CFST columns and the traditional station structure with RRC columns. The influence of the prefabricated CFST column with quick-connection device on the peak acceleration of the underground structure is reduced when the earthquake period is larger than $1 \mathrm{~s}$, and the response spectra of the three different structures are very close. This means that the vibration period of the main structure of the subway station before and after changing the middle column has little change.

\subsection{Earthquake Damage of the Underground Structure.} For further analyzing the influence of different types of middle columns on the seismic performance of the underground structure, Figures 10 and 11 show the seismic tension damage of the structure using the RRC, CRC, and CFST columns under the two conditions of Kobe wave: $\mathrm{PBA}=0.3 \mathrm{~g}$ (moderate earthquake) and $\mathrm{PBA}=0.5 \mathrm{~g}$ (strong earthquake). DAMAGET represents the tensile damage factor of the concrete material. For DAMAGET $=1$, it indicates that the concrete material is completely damaged by tensile damage. "Avg 75\%" means that when the relative node variable is less than this value, the result of this node will be averaged.

It can be seen from Figure 10 that when $\mathrm{PBA}=0.3 \mathrm{~g}$, the main structure of the station using the traditional connection method has obvious earthquake tensile damage at the connections between the top and bottom plates and the sidewalls and the connection between the ends of the column and the longitudinal beams. Compared with the RRC column, the CRC column has less damage at the ends, and tthe damage at the connections between the two ends of the column and the longitudinal beam is slightly less than that of the structure with the RRC column, which indicates that the underground structure with the CRC column has a higher antiseismic performance. The damage at the top slab of the structure with the CFST column is slightly increased, and the chamfer at the bottom of the sidewall showed the through-section damage, while there is no obvious earthquake tensile damage at the top and bottom ends of the middle column and the connection between the column and the longitudinal beam. The reason for this phenomenon is that two pieces of steel ring-clad joints are set on the top and bottom of the quickconnection device. The steel joint covers the CFST column and the restraint between the CFST column and the longitudinal beam is greatly reduced, thereby avoiding the possible stress concentration at the connection between them. Besides, at the outer side of the CFST column, there is a layer of steel outer skin that has good ductility under the action of earthquake loads and can effectively protect the inner concrete of the middle column. At the same time, we found that, in the traditional station structure (conditions 1 and 2), the connection between the middle column and the longitudinal beam also has serious earthquake damage, which cannot be simulated by the previous 2D FEM model. As a matter of fact, in the process of $2 \mathrm{D}$ model, the real station is simplified as plane model. In the meantime, the column is simplified as a wall. Its relevant properties' parameters are reduced based on the distance of columns, leading to an obvious contrast on the strength between the column and longitudinal beam. Under the action of seismic load, the middle column with obviously lower strength will take the lead in tensile failure and compression failure, resulting in more serious earthquake damage. Therefore, compared with the $2 \mathrm{D}$ model, the 3D model can better reflect the real earthquake damage of the station.

As for the results corresponding to the Kobe wave with $\mathrm{PBA}=0.5 \mathrm{~g}$, as shown in Figure 11, the seismic tensile damage of the three underground structures with different types of columns at the connections between the plates and the sidewalls is significantly increased. The seismic damage completely penetrates the entire section and develops a large-scale damage cross-connected area. The whole cross sections at the ends of the columns without isolated devices (RRC and CRC) were fully tensile-damaged, and both ends of the plates and the lower parts of the two sidewalls also suffered severe damage. For the structure with the CRC 


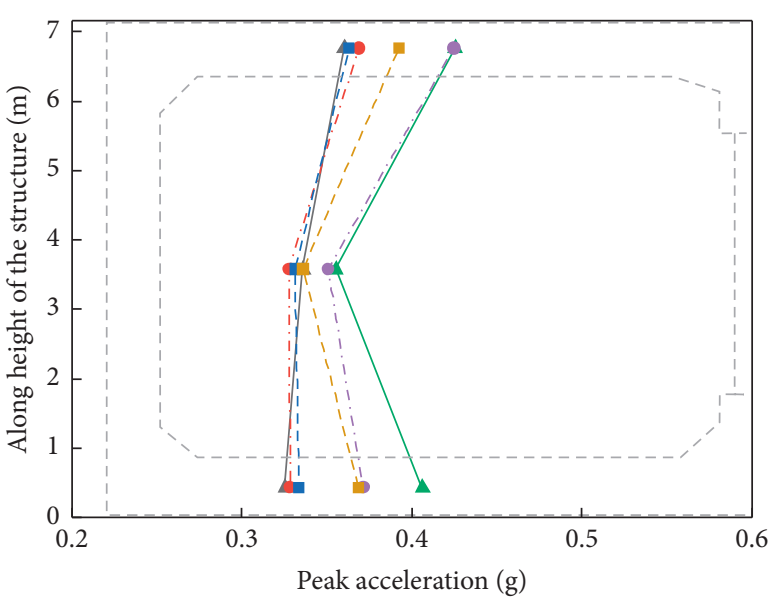

Kobe wave
- $0.3 \mathrm{~g}$ (RRC column) - $-0.5 \mathrm{~g}$ (RRC column)

$\longrightarrow 0.3 \mathrm{~g}$ (CRC column) $\rightarrow 0.5 \mathrm{~g}$ (CRC column)

$\simeq 0.3 \mathrm{~g}$ (CFST column) $\_0.5 \mathrm{~g}$ (CFST column)

(a)

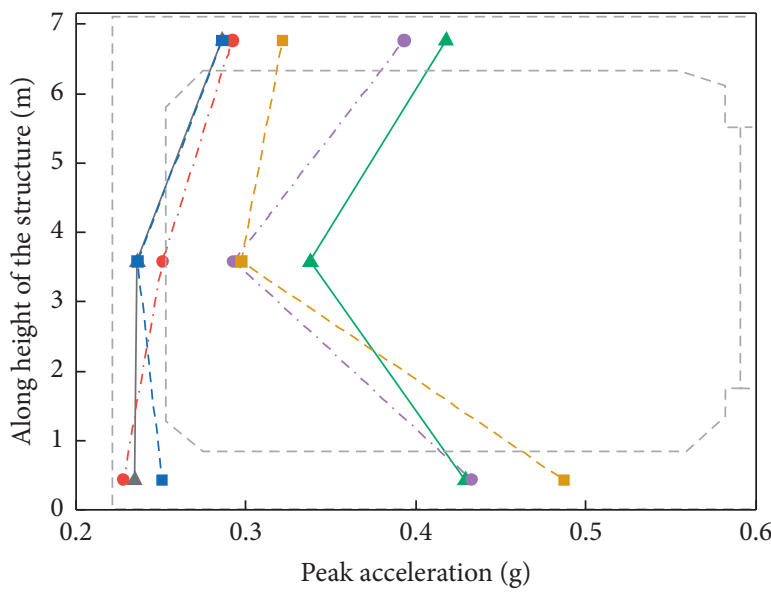

Wolong wave

- - 0.3 g (RRC column) - - $0.5 \mathrm{~g}$ (RRC column)

$\bullet-0.3 \mathrm{~g}$ (CRC column) $\quad-0.5 \mathrm{~g}$ (CRC column)

$\triangle 0.3 \mathrm{~g}$ (CFST column) $\_0.5 \mathrm{~g}$ (CFST column)

(c)

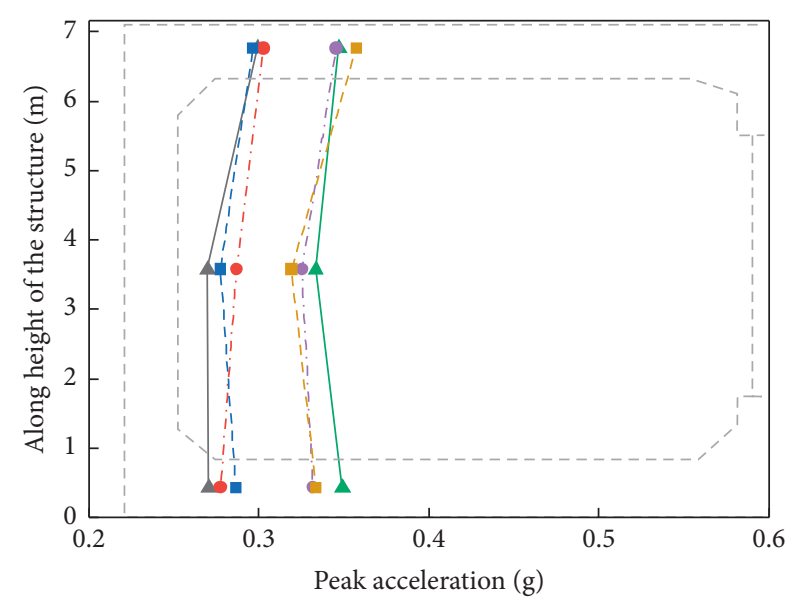

El-Centro wave

- $-0.3 \mathrm{~g}$ (RRC column) - - $0.5 \mathrm{~g}$ (RRC column)

$\bullet-0.3 \mathrm{~g}$ (CRC column) $\rightarrow 0.5 \mathrm{~g}$ (CRC column)

$\leftarrow 0.3 \mathrm{~g}$ (CFST column) $\leftarrow 0.5 \mathrm{~g}(\mathrm{CFST}$ column $)$

(b)

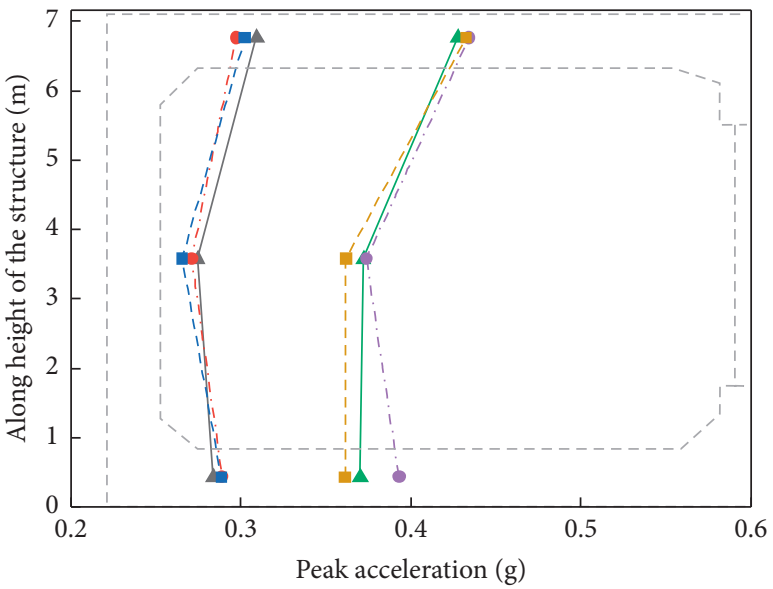

Shifang wave

- $0.3 \mathrm{~g}$ (RRC column) $-0.5 \mathrm{~g}$ (RRC column)

$\rightarrow-0.3 \mathrm{~g}$ (CRC column) $\rightarrow 0.5 \mathrm{~g}$ (CRC column)

$\leftarrow 0.3 \mathrm{~g}$ (CFST column) $\leftarrow$ 0.5g (CFST column)

(d)

FIgURE 7: Comparison of peak accelerations of the structures with different columns.

column, the damage at the ends of the column and the top slab is less than that of the structure with the RRC columns, and similar slight damage can also be observed at the upper and lower connections of the middle column with the longitudinal beams. Compared with the structure with RRC or CRC column, the station structure with CFST column only has slight earthquake tensile damage at the ends of the middle column. The damage at the connection between the middle column and the bottom plate is also significantly reduced. However, the damaged area at the connections between the slabs and the sidewalls is slightly larger than those of the underground structure with RRC or CRC column, and relatively serious damage also appeared on the upper part of the left sidewall. Therefore, the CFST column and quick-connection device proposed in this article can be set up to effectively reduce the seismic damage at the ends of the middle column of the underground structure and its nearby top and bottom slabs.

The subway station structure is mainly subjected to severe tensile damage caused by a strong earthquake but less obvious earthquake compression damage. In this study, when the amplitude of PBA is small, the station structure does not show obvious seismic compression damage. Figure 12 shows the seismic compression damage of the underground structure under the excitation of Kobe wave with $\mathrm{PBA}=0.5 \mathrm{~g}$. It can be seen from the figure that the RRC or CRC column which is connected with the station structure through complete constraints has obvious earthquake compression damage, and the damage of the CRC column is slightly greater than that of the RRC column. This is because, for the same moment of 


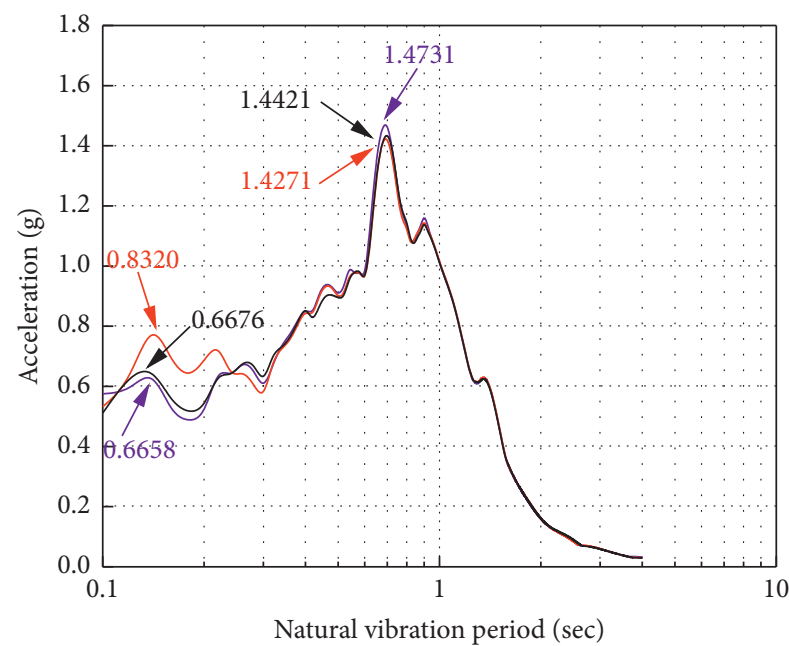

- RRC column

— CRC column

— CFST column

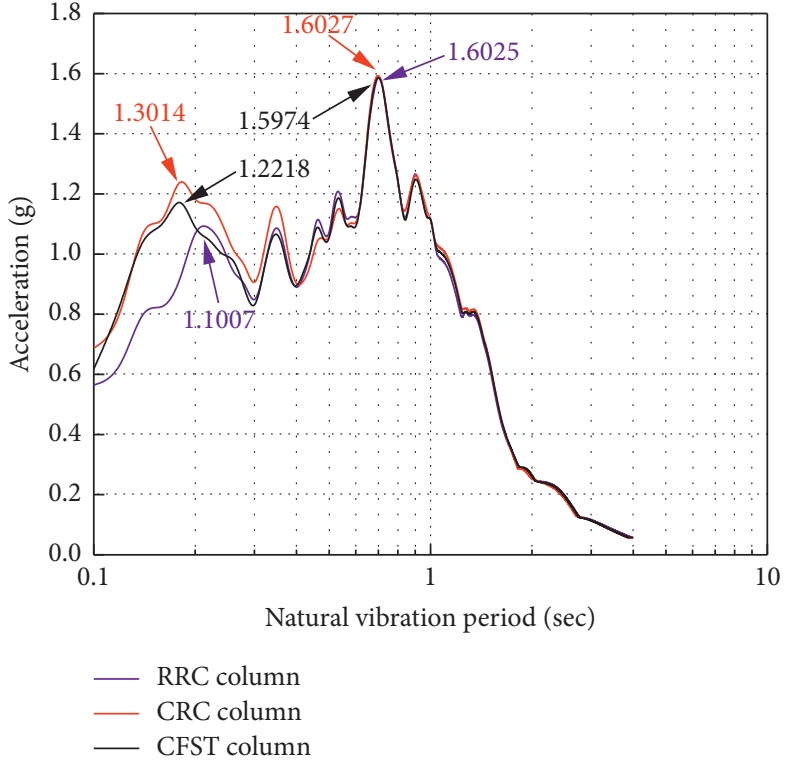

(b)

FIgURE 8: Acceleration response spectra at the top plate of the underground structure under Kobe wave.

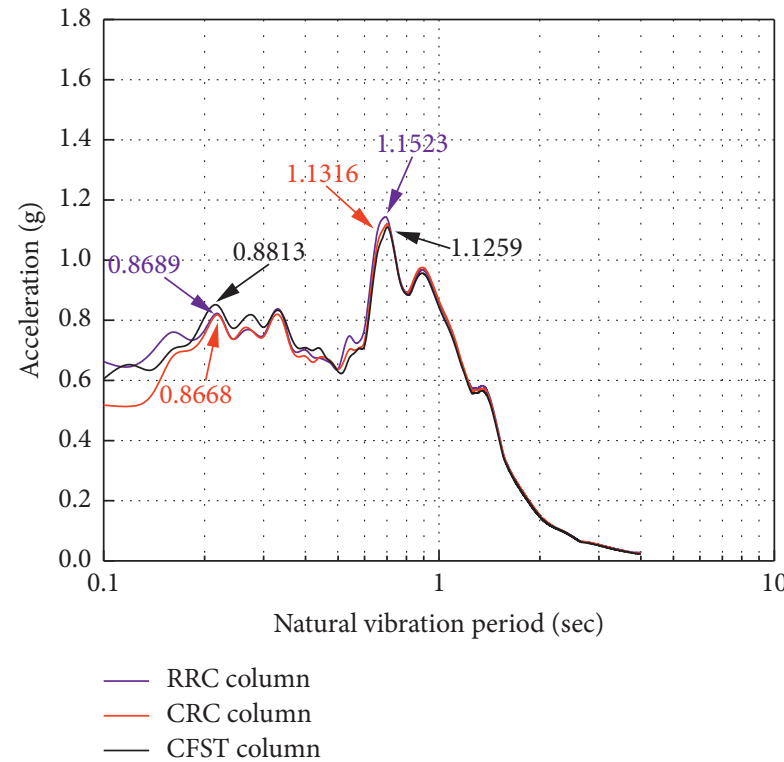

(a)

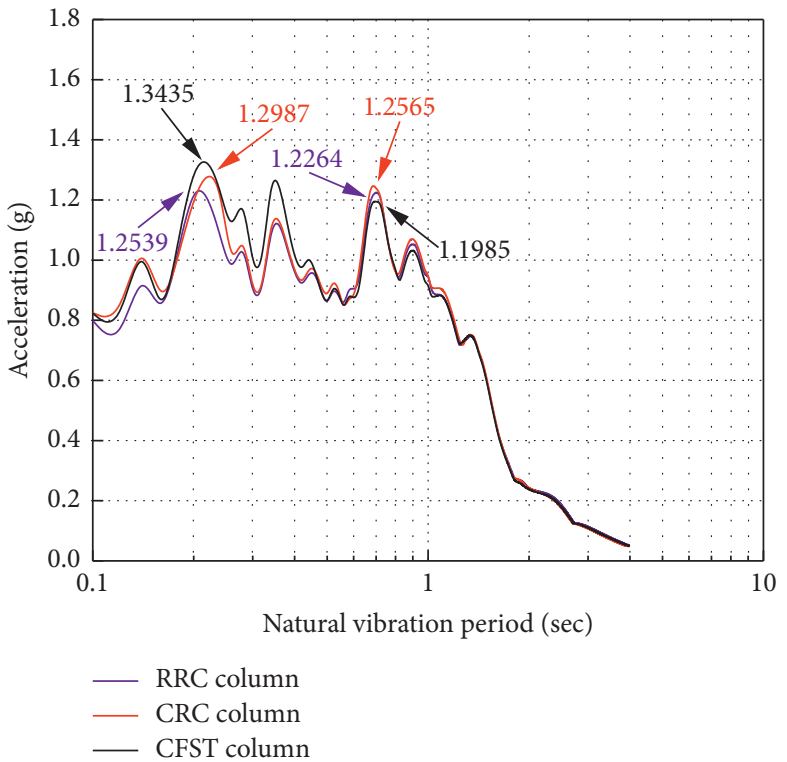

(b)

FIGURE 9: Acceleration response spectra at the bottom of the underground structure under Kobe wave.

inertia, the cross-sectional area of the CRC column is smaller, leading to a larger ratio of axial pressure. However, it is interesting that the station structure with the CFST column does not show obvious seismic compression damage. Therefore, it can be concluded that the CFST column and its quick-connection device proposed in this paper can also effectively alleviate the seismic compression damage of the middle column of the station structure.

The actual earthquake damage of the DAIKAI station can be observed in [34]. It can be found that the deformation of the damaged station structure was "M" shape (as shown in Figure 13(b)). Serious tensile damage occurred at the top slab of the structure, especially in areas where the top slab connects with the sidewalls and the middle columns, resulting in extensive tensile cracking damage to the section. The tensile cracks of the station are shown in Figure 13(a). Under the combined action of the seismic load and the overlying soil pressure, the middle columns of the station structure suffered serious tensile damage and compression damage, which caused the top of the station to collapse. The 


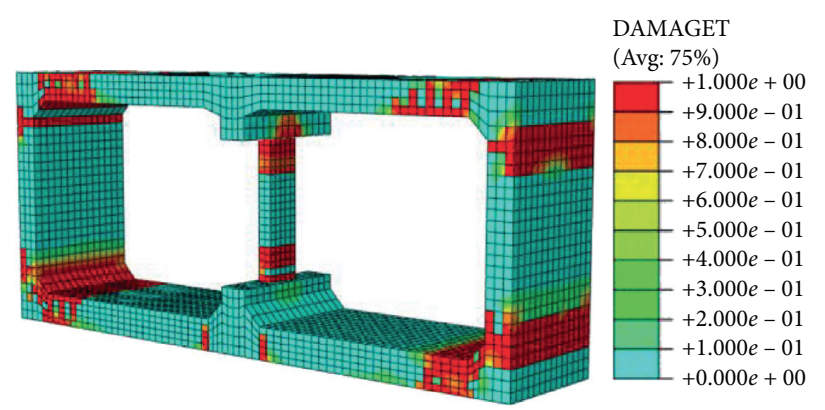

(a)

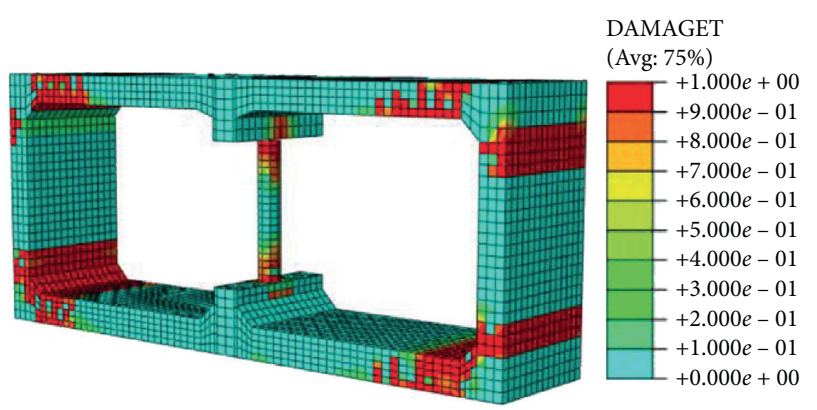

(b)

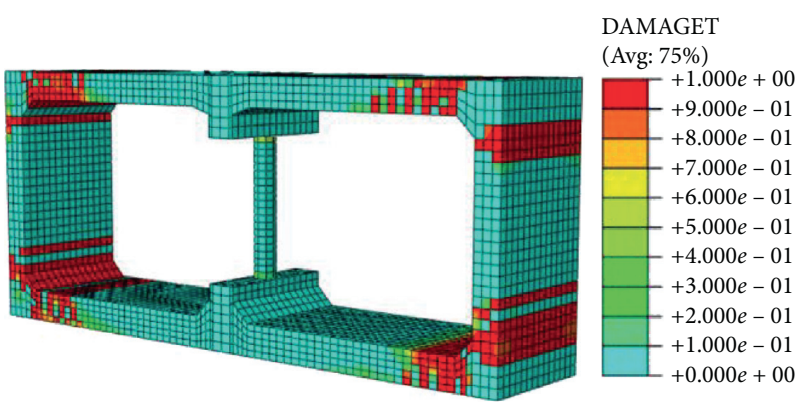

(c)

FIGURE 10: Seismic tension damage of underground structure with PBA $=0.3 \mathrm{~g}$ of Kobe wave. Station structure with (a) RRC columns, (b) CRC columns, and (c) CFST columns.

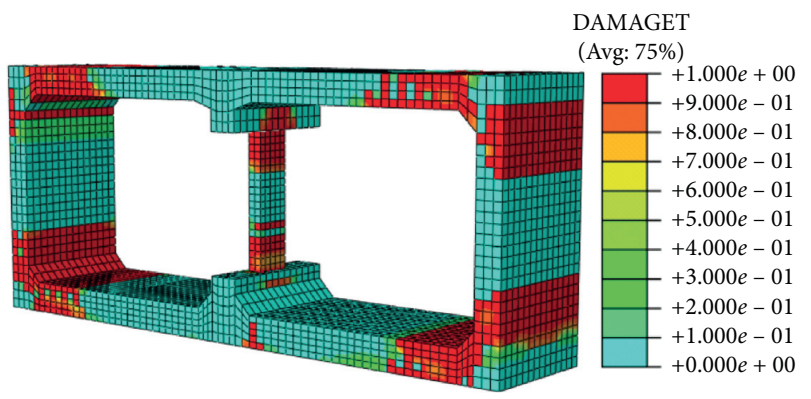

(a)

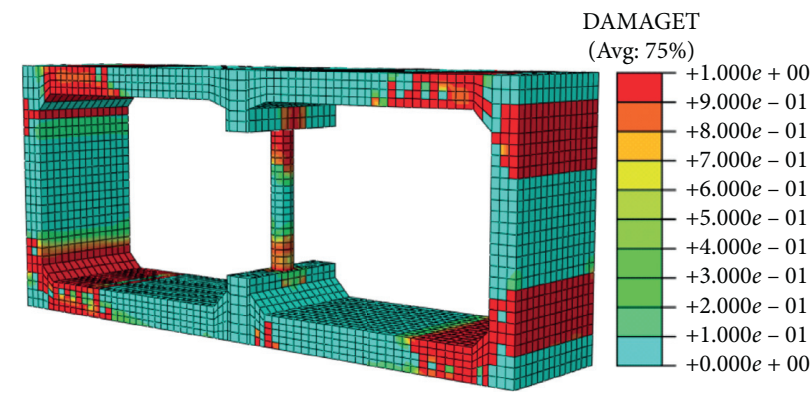

(b)

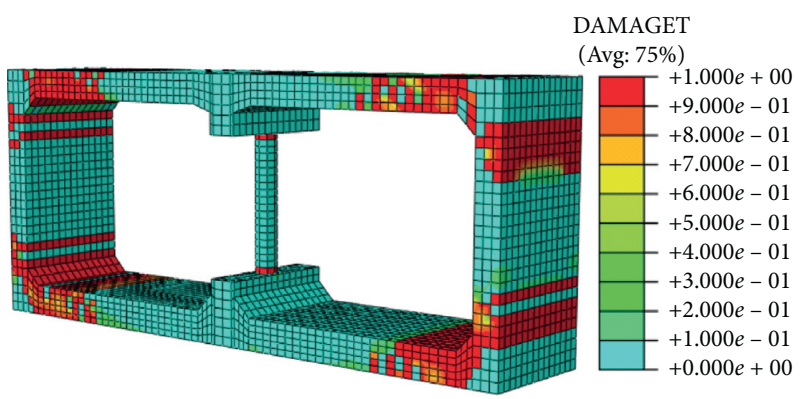

(c)

FIgURE 11: Seismic tension damage of underground structure with PBA $=0.5 \mathrm{~g}$ of Kobe wave. Station structure with (a) RRC columns, (b) CRC columns, and (c) CFST columns.

seismic damage of the DAIKAI subway station obtained by the numerical simulation in this paper is also consistent with the actual earthquake damage shown in Figure 13(b), which shows that the finite element model established in this paper can reproduce the seismic damage of the DAIKAI station.
This also shows that, under the action of strong earthquake load, the middle columns are the vulnerable components of the underground structure. It is necessary to improve the rapid recovery ability of the middle columns of the station after the earthquake. 


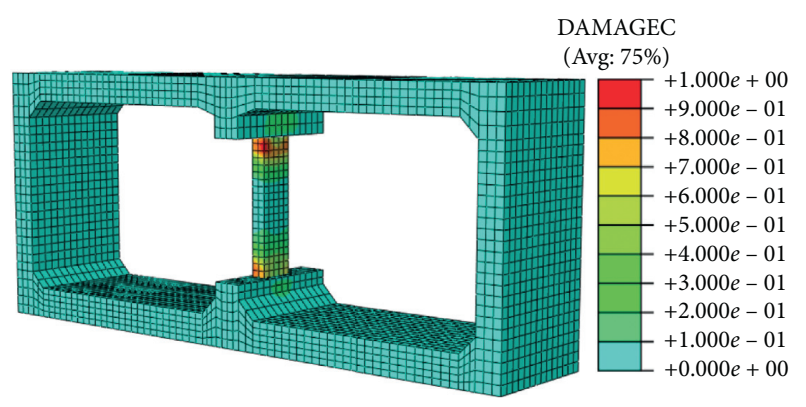

(a)

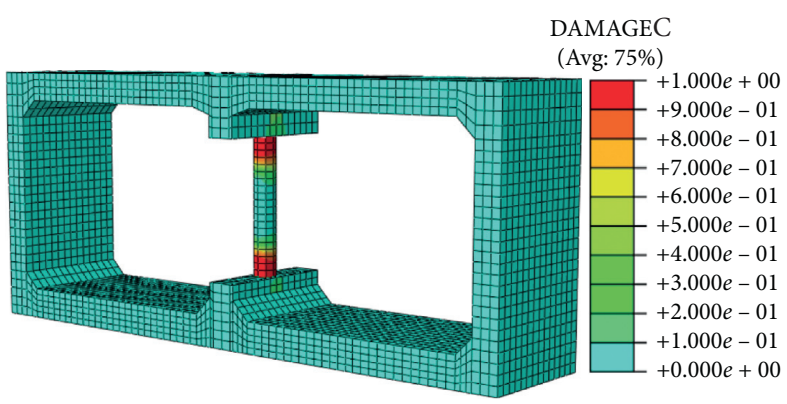

(b)

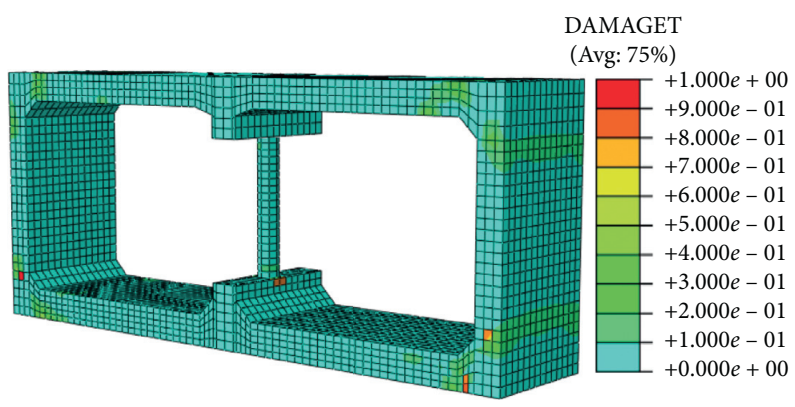

(c)

FIGURE 12: Seismic compress damage of underground structure with PBA $=0.5 \mathrm{~g}$ of Kobe wave. Station structure with (a) RRC columns, (b) CRC columns, and (c) CFST columns.

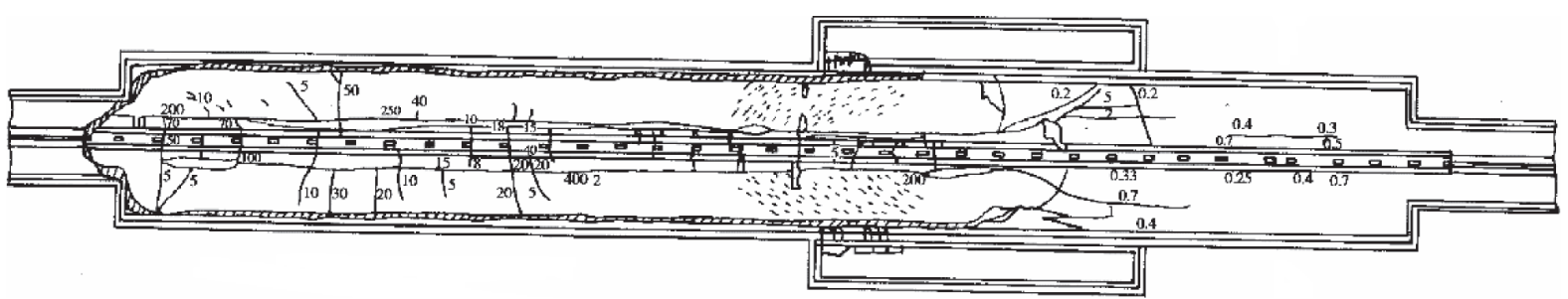

(a)

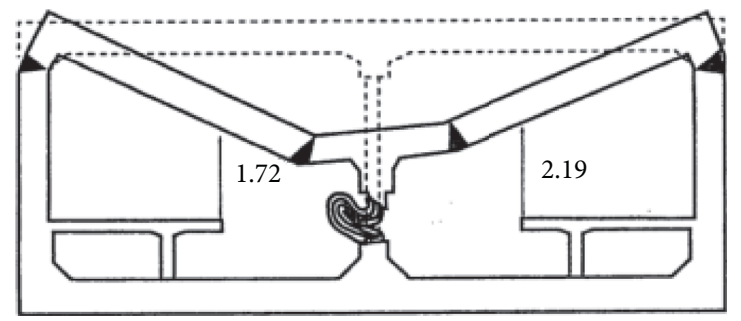

(b)

Figure 13: The actual seismic damage of DAIKAI subway station. (a) Tension cracks at DAIKAI subway station [34]. (b) Earthquake collapse of DAIKAI subway station [34].

3.4. Stress Condition of Steel Ring-Wrap Joints. To study the dynamic characteristics of the CFST column and its quickconnecting device during earthquakes, the steel ring-wrap joint with large deformation at the bottom of the column was selected for dynamic stress analysis. When the PBA of the Kobe wave is $0.3 \mathrm{~g}$ and $0.5 \mathrm{~g}$, the stress at the steel ring-wrap joint at the bottom of the column reaches the peak at $9.90 \mathrm{~s}$ and $8.62 \mathrm{~s}$, respectively. The peak Mises stress of the steel ring-wrap joint is shown in Figure 14. With the increase of PBA, the peak stress of the steel ring-wrap joint increases.
Due to the use of full-seam welding between the two rings of the wrap joint, the end of the column of the CFST column is wrapped inside. Therefore, under the action of seismic load, a certain stress concentration will appear around the contact surface between the wrap joint and the column. For reducing the stress and deformation of the steel ring-wrap joint, it is possible to consider using high-grade steel to make the connection device of the CFST column, improving the overall strength and seismic performance of the underground structure under the severe earthquake. 


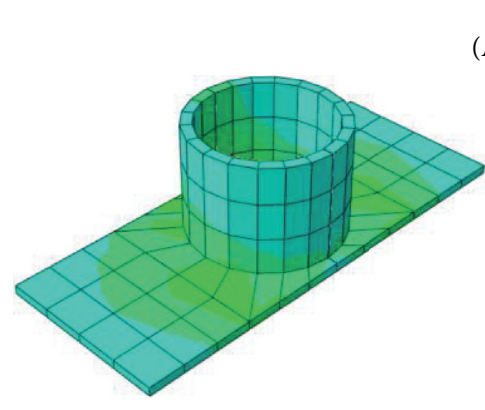

(a)

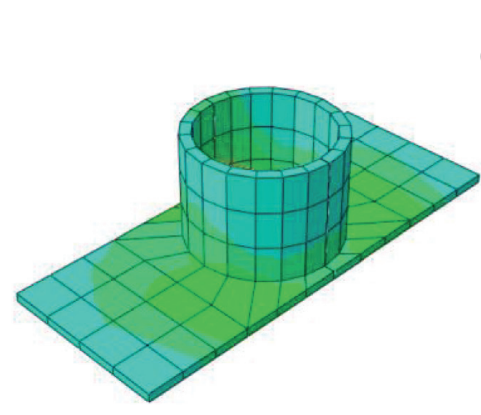

(c)
$\mathrm{S}$, mises

(Avg: 75\%)

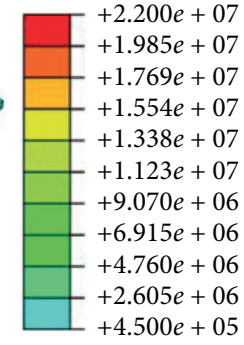

$\mathrm{S}$, mises

(Avg: 75\%)

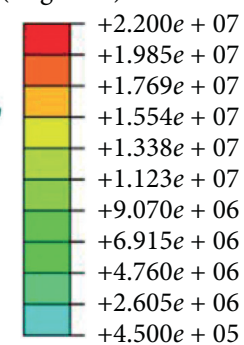

$+4.500 e+05$

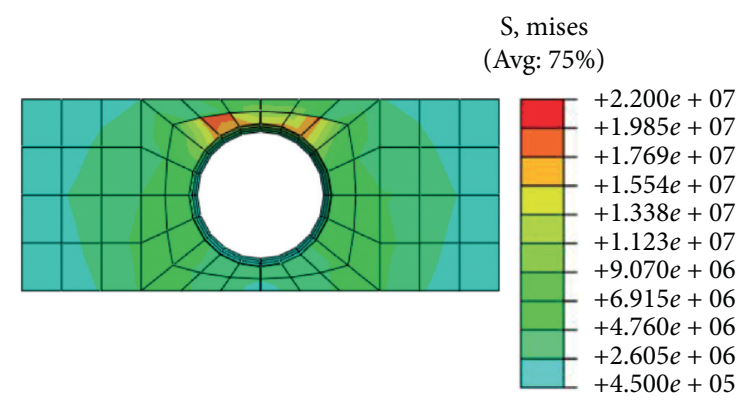

(b)

$\mathrm{S}$, mises

(Avg: 75\%)
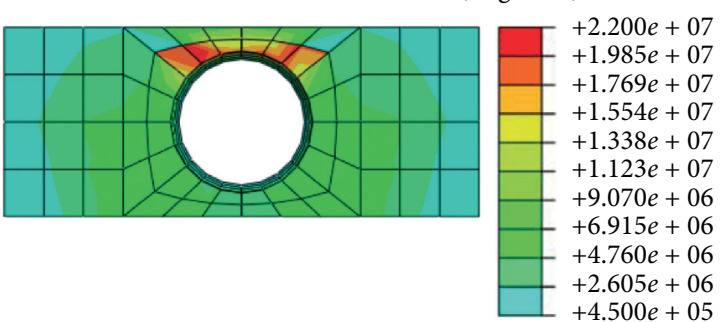

(d)

Figure 14: Peak Mises stress of steel ring-clad joints under the Kobe wave. (a) Lateral view (PBA =0.3 g), (b) upward view (PBA=0.3 g), (c) lateral view $(\mathrm{PBA}=0.5 \mathrm{~g})$, and $(\mathrm{d})$ upward view $(\mathrm{PBA}=0.5 \mathrm{~g})$.

In conclusion, the CFST column with the quick-connection device proposed in this paper has good seismic performance and can improve the seismic performance of the underground structure. For the same moment of inertia of the section, the seismic compressive damage of the CRC column is lighter than that of the RRC column, but the seismic compressive damage of the CRC column is increased due to the smaller cross-sectional area. According to the above analysis, it is suggested that the prefabricated CFST column with the quick-connection device should be used first when strong earthquakes occur, while the CRC column should be preferred when the medium or small earthquake happens.

3.5. Time History of Key Nodes in the Station Structure. To furtherly investigate the effect of the CFST column and its quick-connection device on the seismic response of underground station structure, the time history curve of the dynamic internal force response was also presented at some key nodes of the station structure. A total of 6 key nodes have been selected, which are, respectively, distributed at the top and bottom chamfer of the sidewall, the ends of the middle column, and the edge of the plate. According to the previous study, these places are the vulnerable part in the earthquake. The distribution of key nodes in the structure is shown in Figure 15.

3.5.1. Time History of Bending Moment of the Station Structure. It can be seen from Figure 16 that nodes A, B, C, and $\mathrm{D}$ are in the state of cyclic tension and compression, and the peak of the dynamic bending moment at the top chamfer of the sidewall is significantly smaller than that at the bottom chamfering. Compared with the structure with RRC or CRC column, the dynamic bending moment at the section of some members of the structure with CFST columns increases slightly, corresponding to the dynamic damage of the concrete. The reason is that the CFST column is not completely fixed with the station structure, allowing a certain elastic slip when an earthquake occurs. However, the RRC or CRC column and the station structure are a one-piece pouring. There is no relative slip or separation between the RRC/CRC column and the structure so that the overall stiffness of the station structure is slightly higher. Besides, node $\mathrm{E}$ and node $\mathrm{F}$ which are connected through complete constraints with the station structure also show a certain cyclic tensile and compressive stress state when subjected to a strong earthquake. The steel ring-wrap joint of the quickconnection device has good ductility, which can better protect the middle column. Therefore, in the prefabricated structure with CFST column and quick-connection device, the peak of the dynamic tensile stress of nodes $\mathrm{E}$ and $\mathrm{F}$ is significantly reduced compared with those of the underground structure without isolated devices and presents a certain elastic hysteresis.

3.5.2. Time History of Axial Force of the Middle Column. The time history of the response of the key nodes at the ends of the column under the conditions of the Kobe wave with $\mathrm{PBA}=0.3 \mathrm{~g}$ and $0.5 \mathrm{~g}$ is shown in Figure 17. As can be seen from the figure, when the PBA increases from $0.3 \mathrm{~g}$ to $0.5 \mathrm{~g}$, 


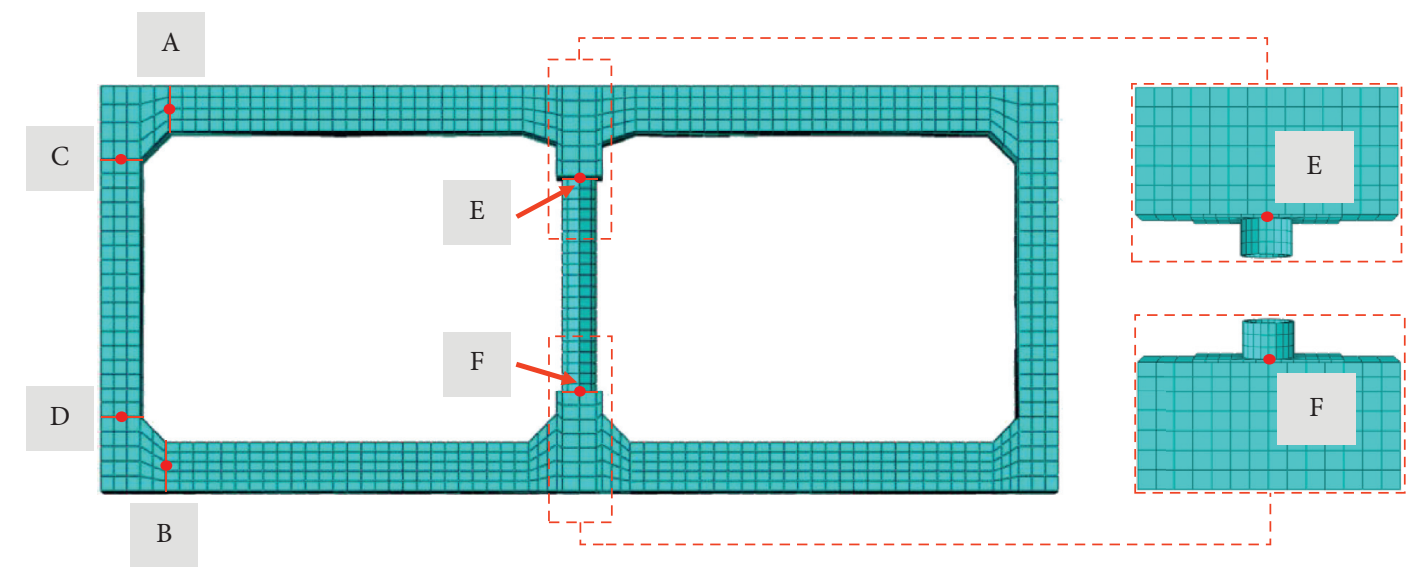

Figure 15: The distribution of key nodes in the structure.

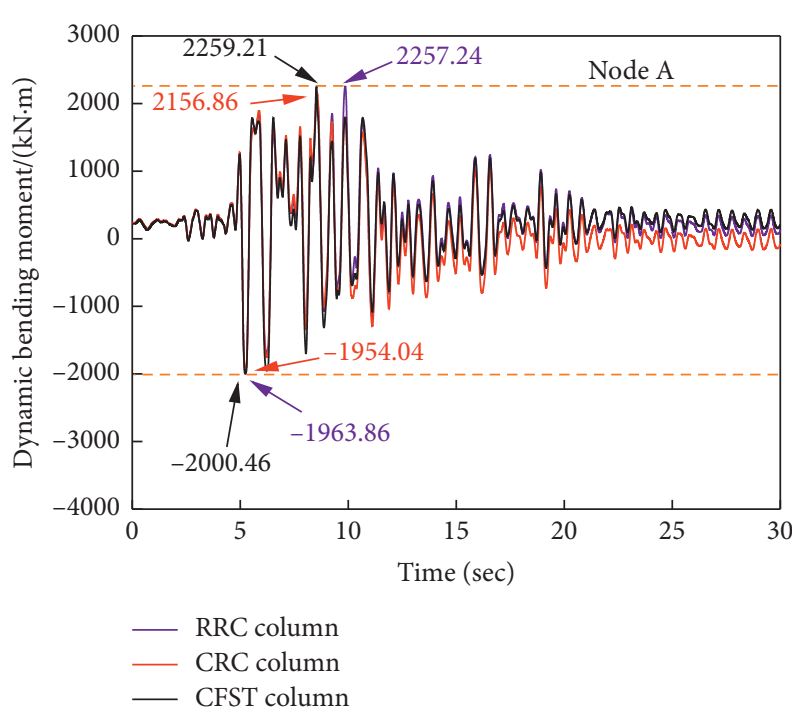

(a)

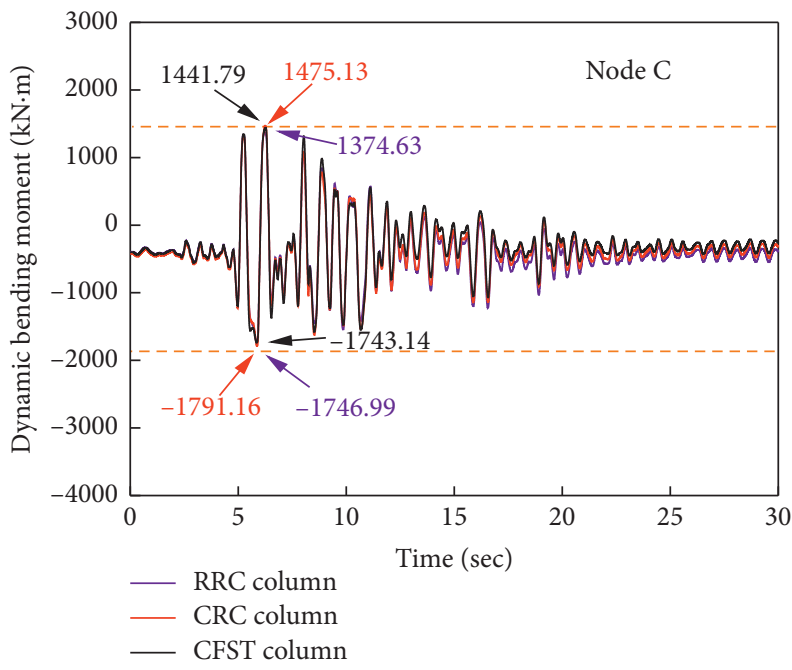

(c)

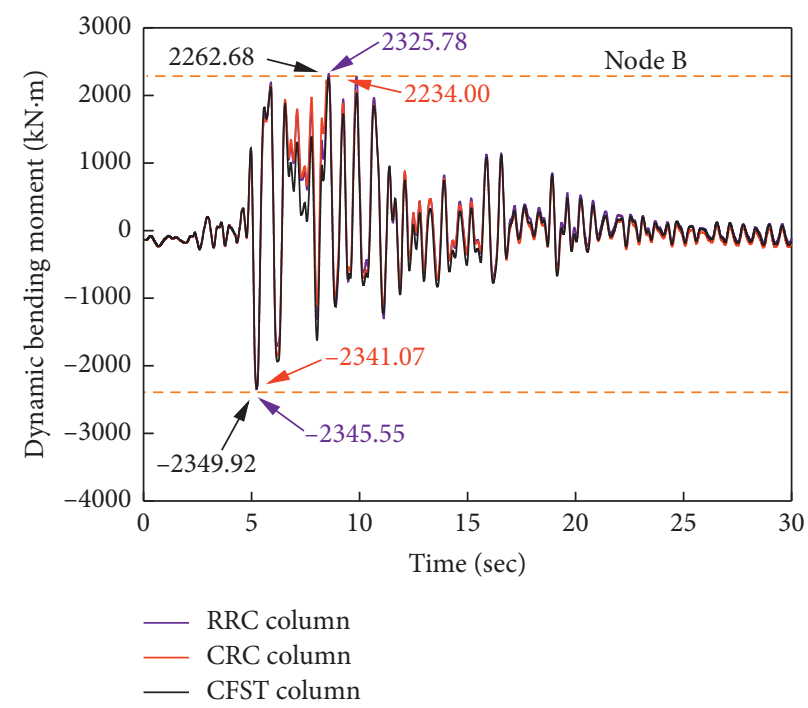

(b)

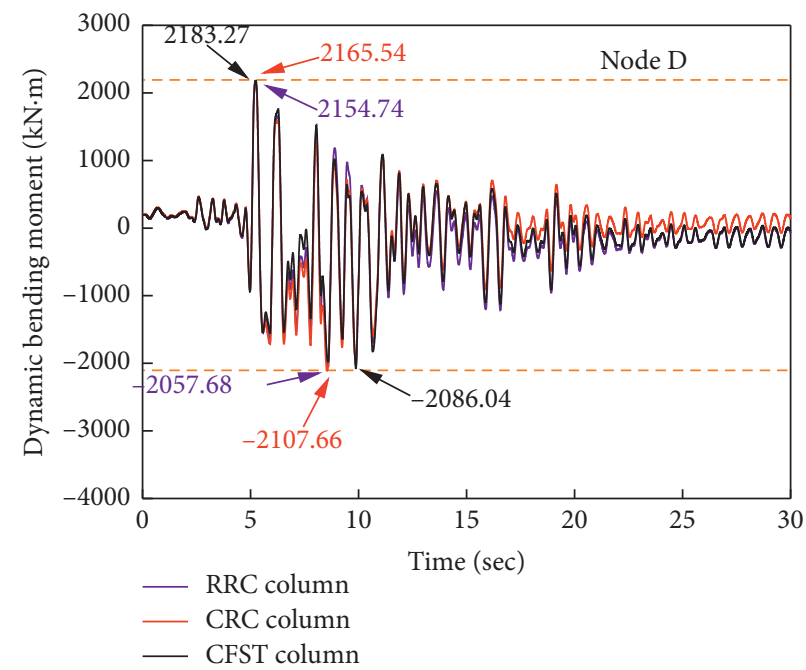

(d)

Figure 16: Continued. 

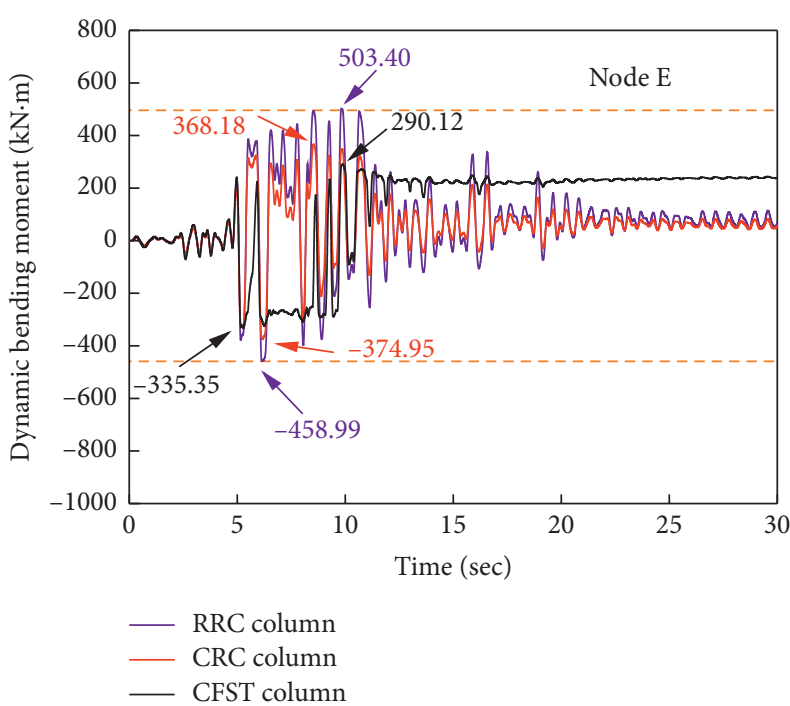

(e)

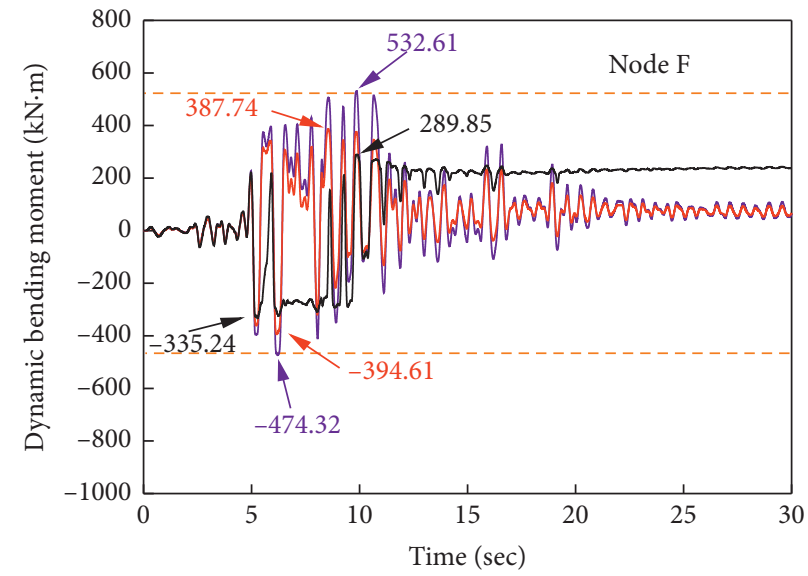

— RRC column

- CRC column

_ CFST column

FIGURE 16: Time history of the dynamic bending moment for critical nodes of the station under the Kobe wave with PBA=0.3 g.

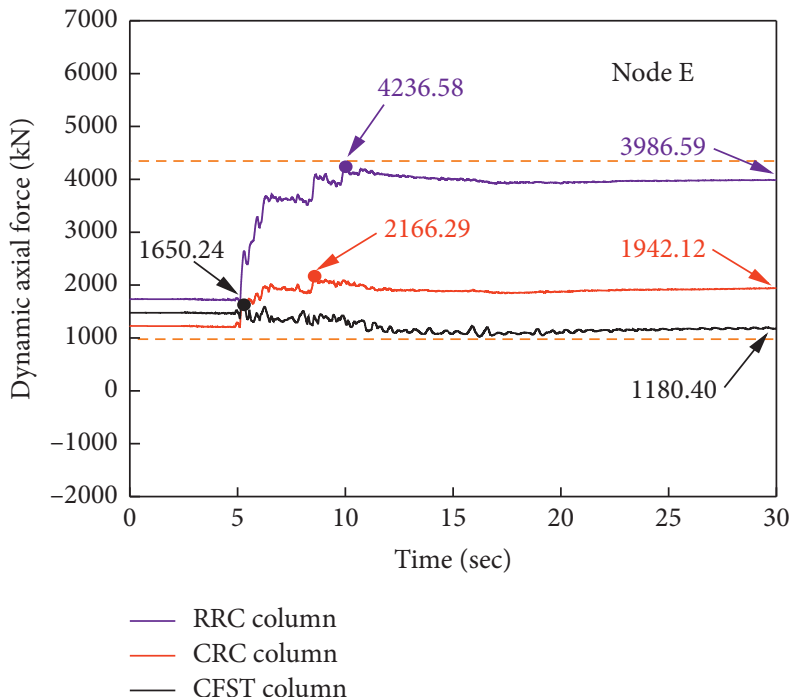

(a)

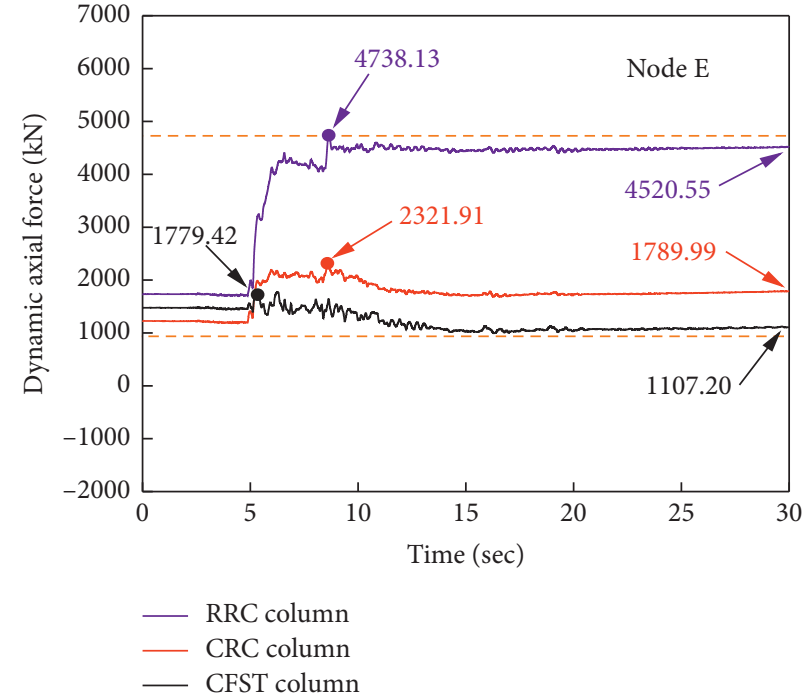

(b)

Figure 17: Continued. 


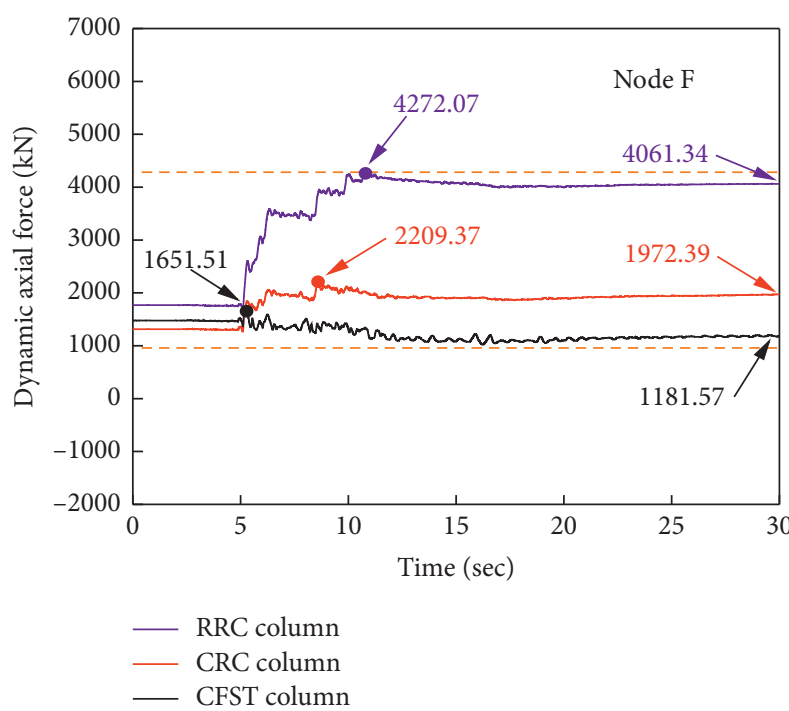

(c)

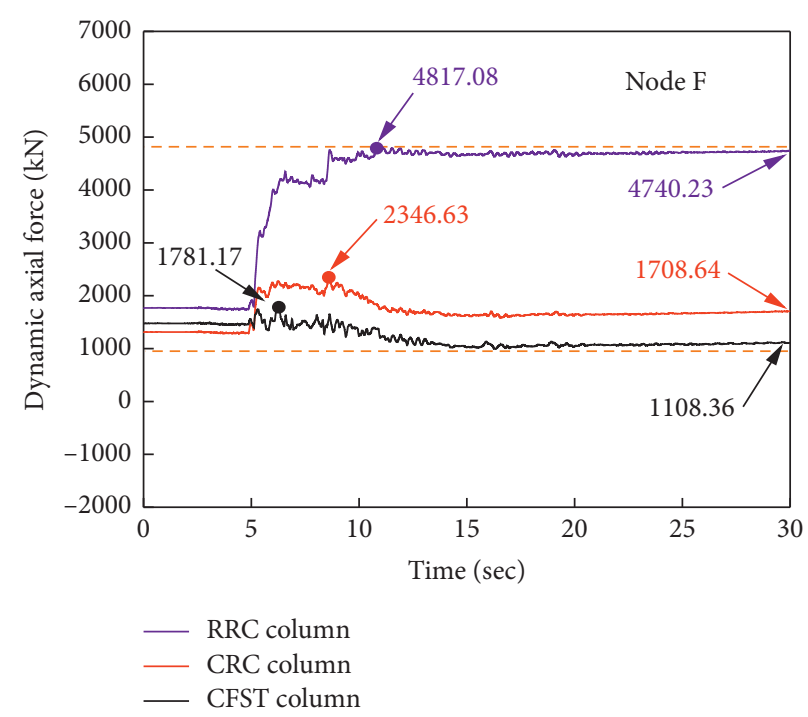

(d)

FIgURE 17: Time history of axial force for the key nodes of the station subjected to the Kobe wave with PBA $=0.3 \mathrm{~g}$ and $0.5 \mathrm{~g}$. (a) Axial force on the top of the middle column ( $\mathrm{PBA}=0.3 \mathrm{~g})$. (b) Axial force on the top of the middle column ( $\mathrm{PBA}=0.5 \mathrm{~g})$. (c) Axial force on the bottom of the middle column $(\mathrm{PBA}=0.3 \mathrm{~g})$. ( $\mathrm{d})$ Axial force on the bottom of the middle column $(\mathrm{PBA}=0.5 \mathrm{~g})$.
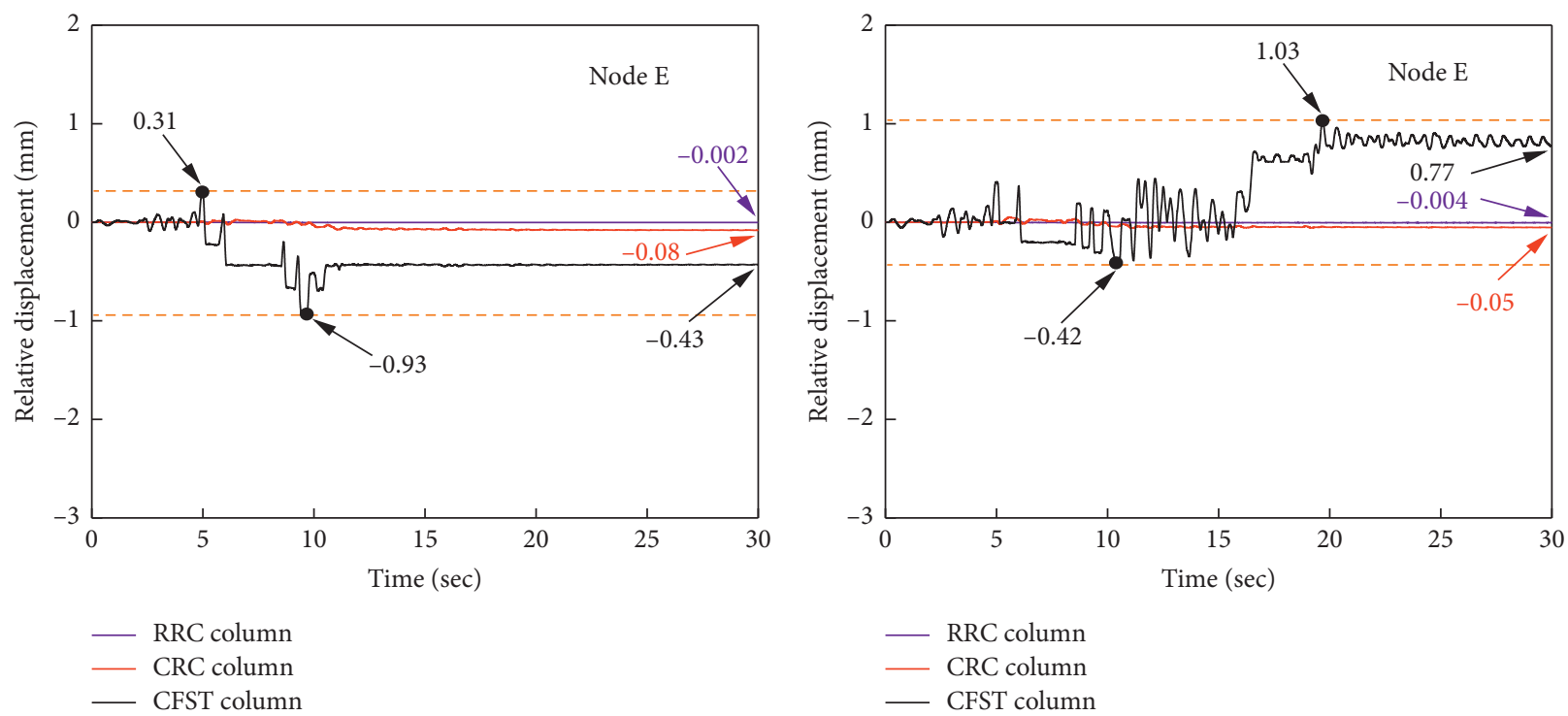

(a)

(b)

Figure 18: Continued. 


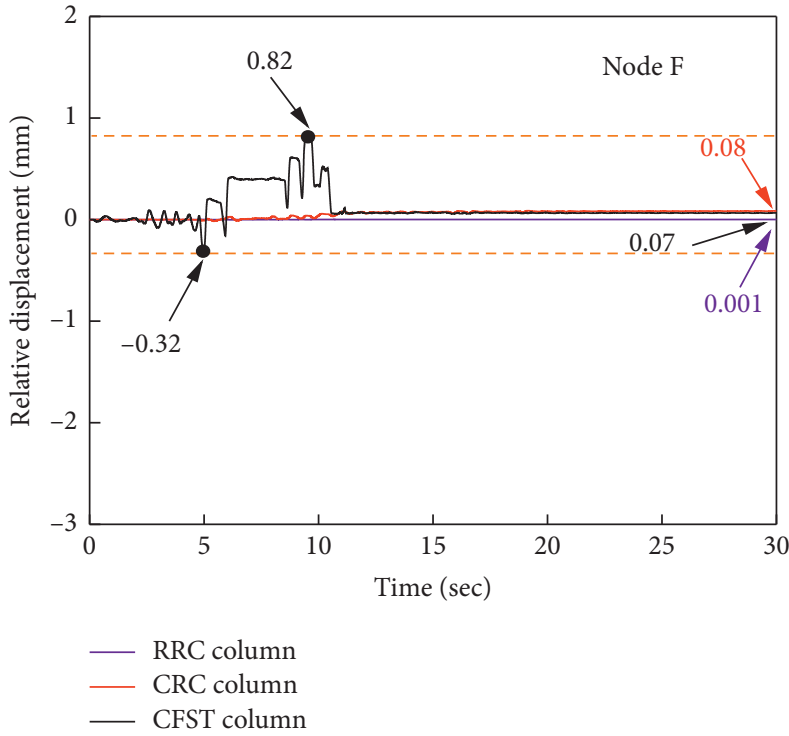

(c)

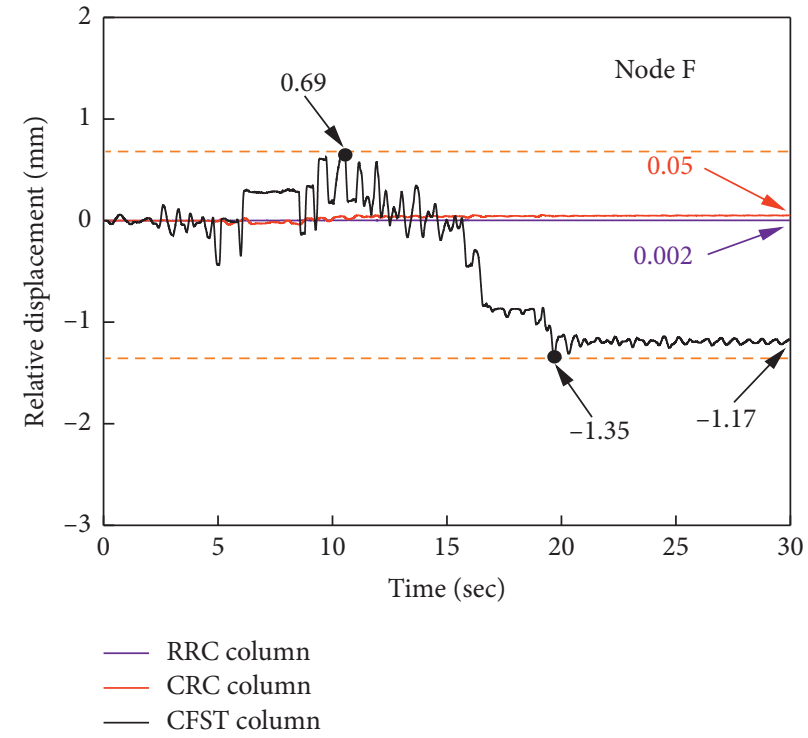

(d)

FIGURE 18: Relative displacement history between the intermediate column and the longitudinal beam under the Kobe wave. (a) The relative displacement at the top of the column $(\mathrm{PBA}=0.3 \mathrm{~g})$. (b) The relative displacement at the top of the column $(\mathrm{PBA}=0.5 \mathrm{~g})$. (c) The relative displacement at the bottom of the column $(\mathrm{PBA}=0.3 \mathrm{~g})$. (d) The relative displacement at the bottom of the column $(\mathrm{PBA}=0.5 \mathrm{~g})$.

the axial force acting on the middle column increases rapidly. Compared to the RRC column, the CRC column suffers less axial force, which makes its damage smaller. The quick-connection device changes the force acting on the CFST column. The middle column is no longer cast together with the main structure, but there is a contact surface between it and the longitudinal beam. According to Figure 17, the axial force acting on the CFST column is slightly smaller than that of the CRC column. The variation of the axial force time history is completely corresponding to the damage. In particular, the residual axial force acting on the CFST column is greatly smaller than that of the CRC column, and that of the RRC column is greatly larger than that of the CRC column.

\subsection{Lateral Residual Deformation at the Top and Bottom of} Prefabricated CFST Columns. To reflect the self-recovery ability of the lateral deformation of the prefabricated CFST column during the earthquake, the relative displacements between the CFST column and the longitudinal beam were extracted. As can be seen from Figure 18, compared with the RRC and CRC columns, the CFST column and its quick-connection device will slightly increase the relative displacement between the middle column and the longitudinal beam. The steel quick-connection device has good ductility, and the relative displacement of the CFST column finally tends to a constant value under the action of seismic load. The residual deformation of the middle column is all less than $1.2 \mathrm{~mm}$, indicating that the prefabricated CFST column has a small offset and has a good antiseismic selfreset ability.

\section{Conclusion}

According to the characteristics of station structure with CFST columns proposed in this paper, a 3D integral finite element model for the soil-underground structure nonlinear dynamic interaction is established. To show the difference of the seismic performance of the underground structures with the different middle columns, the 3D integral finite element analysis models of the traditional nonassembled station structure with the RRC and CRC columns are also established. The specific conclusions and findings are as follows:

(1). For the same input peak acceleration of bedrock motion (PBA), the amplitude of IDA of the station structure with the RRC columns is the largest, followed by the station structure with the prefabricated CFST columns and the structure with the CRC columns. It is fully demonstrated that, compared with the RRC column, the CRC column has better seismic performance and can effectively enhance the antilateral stiffness of the structure.

(2). In terms of the seismic damage to the underground structure with the prefabricated CFST columns, the earthquake damage degree of the station structure is slightly aggravated with the increase of PBA. The bending moment and axial force time history of the key section of the main structure also reflect this point. On the cross section of the middle column, the CFST column has a layer of steel outer skin, which allows the CFST column to have a certain slip or separation relative to the longitudinal beams. This can effectively protect the middle column of the 
underground station from serious earthquake damage and improve the overall seismic performance of the underground station structure.

(3). As for the dynamic stress of the quick-connection device, with the increase of PBA, the steel cladding of the top and bottom of the connecting device and the steel outer skin of the prefabricated CFST column are still within the elastic-plastic range, which has a high working strength. The lateral residual relative displacement of the prefabricated CFST column is less than $1.2 \mathrm{~mm}$, which has a good postearthquake self-reset capability.

(4). The prefabricated CFST column and its quickconnection device can effectively reduce the earthquake damage of the middle column of a single-story frame subway station. Once a strong earthquake occurs, the CFST column proposed in this paper can be dismantled and replaced in time, which improves the overall seismic performance and postearthquake recovery ability of the subway station structure. Thus, the conclusion is appropriate for the shallow-buried single-story underground structure. Because of the soil-structure dynamic interaction (SSI effect), whether it is applicable to the multistory underground structure needs to be further evaluated.

\section{Data Availability}

The data used to support the findings of this study are available from the corresponding author upon request.

\section{Disclosure}

All statements, results, and conclusions are those of the researchers and do not necessarily reflect the views of these entities.

\section{Conflicts of Interest}

The authors declare that they have no conflicts of interest.

\section{Acknowledgments}

The authors are grateful for the research funding provided by the National Natural Science Foundation of China (NSFC, Grant nos. 51978333 and 51778290) and Postgraduate Practice Innovation Program of Jiangsu Province (Grant no. SJCX21_0533). The authors are grateful to the High Performance Computing Center of Nanjing Tech University for supporting the computational resources.

\section{References}

[1] T. C. Gu, "Development status of prefabricated buildings at home and abroad," Standardization of Engineering Construction, vol. 8, pp. 48-51, 2014, in Chinese.

[2] X. Yang, Z. Shi, and F. Lin, "Influence of geometrical parameters on performance of grouted mortise and t joints for application in prefabricated underground structures,"
Advances in Civil Engineering, vol. 2019, no. 19, 14 pages, Article ID 3747982, 2019.

[3] S. Sharma and W. R. Judd, "Underground opening damage from earthquakes," Engineering Geology, vol. 30, no. 3-4, pp. 263-276, 1991.

[4] Y. M. A. Hashash, J. J. Hook, B. Schmidt, and J. I-Chiang Yao, "Seismic design and analysis of underground structures," Tunnelling and Underground Space Technology, vol. 16, no. 4, pp. 247-293, 2001.

[5] N. Yashida and S. Nakamura, "Damage to daikai subway station during the 1995 hyogoken-nunbu earthquake and its investigation," in Proceedings of the 11th World Conference on Earthquake Engineering, vol. 2151, pp. 283-300, Acapulco, Mexico, January 1996.

[6] W. L. Wang, T. T. Wang, J. J. Su, C. H. Lin, C. R. Seng, and T. H. Huang, "Assessment of damage in mountain tunnels due to the Taiwan Chi-Chi earthquake," Tunnelling and Underground Space Technology, vol. 16, pp. 133-150, 2000.

[7] Z. Wang, B. Gao, Y. Jiang, and S. Yuan, "Investigation and assessment on mountain tunnels and geotechnical damage after the Wenchuan earthquake," Science in China - Series E: Technological Sciences, vol. 52, no. 2, pp. 546-558, 2009.

[8] Y. Shen, B. Gao, X. Yang, and S. Tao, "Seismic damage mechanism and dynamic deformation characteristic analysis of mountain tunnel after Wenchuan earthquake," Engineering Geology, vol. 180, pp. 85-98, 2014.

[9] X. L. Du, G. Wang, and D. C. Lu, "Earthquake damage mechanism analysis of dakai metro station by Kobe earthquake," Journal of Disaster Prevention and Mitigation Engineering, vol. 36, no. 2, pp. 165-171, 2016, in Chinese.

[10] T.-H. Lee, D. Park, D. D. Nguyen, and J.-S. Park, "Damage analysis of cut-and-cover tunnel structures under seismic loading," Bulletin of Earthquake Engineering, vol. 14, no. 2, pp. 413-431, 2016.

[11] X. L. Du, C. Ma, D. C. Lu, C. S. Xu, and Z. G. Xu, "Collapse simulation and failure mechanism analysis of the DAIKAI subway station under seismic loads," China Civil Engineering Journal, vol. 50, no. 1, pp. 53-62, 2017, in Chinese.

[12] Z.-Y. Chen, W. Chen, and G.-Q. Bian, "Seismic performance upgrading for underground structures by introducing shear panel dampers," Advances in Structural Engineering, vol. 17, no. 9, pp. 1343-1357, 2014.

[13] X. L. Du, H. T. Liu, D. C. Lu, C. S. Xu, F. R. Luo, and S. M. Li, "Study on seismic performance of sidewall joints in assembled monolithic subway station," China Civil Engineering Journal, vol. 50, no. 4, pp. 38-47, 2017b, in Chinese.

[14] C. Ma, D. Lu, and X. Du, "Seismic performance upgrading for underground structures by introducing sliding isolation bearings," Tunnelling and Underground Space Technology, vol. 74, pp. 1-9, 2018.

[15] H. Liu, Q. Yan, and X. Du, "Seismic performance comparison between precast beam joints and cast-in-place beam joints," Advances in Structural Engineering, vol. 20, no. 9, pp. 12991314, 2017.

[16] P. Ding, L. Tao, X. Yang, J. Zhao, and C. Shi, “Three-dimensional dynamic response analysis of a single-ring structure in a prefabricated subway station," Sustainable Cities and Society, vol. 45, pp. 271-286, 2019.

[17] H. Y. Zhuang and G. X. Chen, "A viscous-plastic model for soft soil under cyclic load-ings. in: geotechnical special publication of ASCE," in Proceedings of the Soil and Rock Behavior and Modeling Proceedings of the Geo-Shanghai Conference, vol. 150, pp. 343-350, Shanghai, China, June 2006. 
[18] H. Y. Zhuang and G. X. Chen, "Improvement of dynamic viscoplastic memorial nested yield surface model of soil," Rock and Soil Mechanics, vol. 30, no. 1, pp. 118-122, 2009, in Chinese.

[19] J. Lee and G. L. Fenves, "Plastic-damage model for cyclic loading of concrete structures," Journal of Engineering Mechanics, vol. 124, no. 8, pp. 892-900, 1998.

[20] J. Lubliner, J. Oliver, S. Oller, and E. Oñate, "A plastic-damage model for concrete," International Journal of Solids and Structures, vol. 25, no. 3, pp. 299-326, 1989.

[21] M. L. Lou, W. J. Wang, T. Zhu, and H. C. Ma, "Soil lateral boundary effect in shaking table model test of soil-structure system," Earthquake Engineering and Engineering Dynamics, vol. 20, no. 2, pp. 30-36, 2000, in Chinese.

[22] H. Zhuang, Z. Hu, X. Wang, and G. Chen, "Seismic responses of a large underground structure in liquefied soils by FEM numerical modelling," Bulletin of Earthquake Engineering, vol. 13, no. 12, pp. 3645-3668, 2015.

[23] H. Huo, A. Bobet, G. Fernández, and J. Ramírez, "Load transfer mechanisms between underground structure and surrounding ground: evaluation of the failure of the daikai station," Journal of Geotechnical and Geoenvironmental Engineering, vol. 131, no. 12, pp. 1522-1533, 2005.

[24] J.-M. Zhang and G. Wang, "Large post-liquefaction deformation of sand, part I: physical mechanism, constitutive description and numerical algorithm," Acta Geotechnica, vol. 7, no. 2, pp. 69-113, 2012.

[25] Z. Y. Chen, W. Y. Li, and L. D. Yang, "Simplified seismic design method for shanghai underground structures in soft soils," Indian Geotechnical Journal, vol. 44, no. 2, pp. 149-155, 2014.

[26] R. Chen, M. Taiebat, R. Wang, and J.-M. Zhang, "Effects of layered liquefiable deposits on the seismic response of an underground structure," Soil Dynamics and Earthquake Engineering, vol. 113, pp. 124-135, 2018.

[27] Bs 5975:2008 + A1, Code of Practice For Temporary Works Procedures And The Permissible Stress Design Of False Work, B S I Standards, London, UK, 2011.

[28] B. C. Wen, Modern Mechanical Design Practical Guide, Machine Press of China, Beijing, China, 2015.

[29] W. K. Tso, T. J. Zhu, and A. C. Heidebrecht, "Engineering implication of ground motion A/V ratio," Soil Dynamics and Earthquake Engineering, vol. 11, no. 3, pp. 133-144, 1992.

[30] Z. Chen, W. Chen, Y. Li, and Y. Yuan, "Shaking table test of a multi-story subway station under pulse-like ground motions," Soil Dynamics and Earthquake Engineering, vol. 82, pp. 111122, 2016.

[31] Z. H. Liao, Theories of Wave Motion For Engineering, Science Press of China, Beijing, China, 2013.

[32] S. K. Maekawa, "The collapse mechanism of a subway station during the Great Hanshin earthquake," Cement and Concrete Composites, vol. 19, no. 3, pp. 241-257, 1997.

[33] H. Y. Zhuang, H. Long, and G. X. Chen, "Analysis of the nonlinear earthquake responses of a large complicated subway underground station," Journal of Earthquake Engineering and Engineering Vibration, vol. 33, no. 2, pp. 192-199, 2013.

[34] H. Iida, T. Hiroto, N. Yoshida, and M. Iwafuji, "Damage to Daikai subway station," Soils and Foundations, vol. 36, pp. 283-300, 1996. 